\title{
Catalyst design for natural-gas upgrading through oxybromination chemistry
}

\section{Journal Article}

\section{Author(s):}

Paunović, Vladimir; Zichittella, Guido; Moser, Maximilian; Amrute, Amol P.; Pérez-Ramírez, Javier

Publication date:

2016-08

Permanent link:

https://doi.org/10.3929/ethz-b-000118963

Rights / license:

In Copyright - Non-Commercial Use Permitted

Originally published in:

Nature Chemistry 8(8), https://doi.org/10.1038/nchem.2522

\section{Funding acknowledgement:}

156107 - Design of oxyhalogenation catalysts for hydrocarbon functionalization (SNF) 


\section{Catalyst design for natural-gas upgrading via oxybromination chemistry}

Vladimir Paunović, Guido Zichittella, Maximilian Moser, Amol P. Amrute, and Javier Pérez-Ramírez*

V. Paunović, G. Zichittella, M. Moser, Dr. A. P. Amrute, and Prof. J. Pérez-Ramírez, Institute for Chemical and Bioengineering, Department of Chemistry and Applied Biosciences, ETH Zurich, Vladimir-Prelog-Weg 1, CH-8093 Zurich, Switzerland.

*E-mail: jpr@chem.ethz.ch 


\begin{abstract}
Natural gas contains large volumes of light alkanes, and its abundant reserves make it an appealing feedstock for value-added chemicals and fuels. However, selectively activating the $\mathrm{C}-\mathrm{H}$ bonds in these useful hydrocarbons is one of the greatest challenges in catalysis. Here we report an attractive oxybromination method for the one-step functionalization of methane under mild conditions that integrates heterogeneously-catalyzed $\mathrm{HBr}$ oxidation with gasphase bromination. Catalyst design strategies to provide optimal synergy between these two processes are discussed. Among many investigated material families, vanadium phosphate (VPO) is identified as the best oxybromination catalyst, providing selectivity to $\mathrm{CH}_{3} \mathrm{Br}$ above $90 \%$ and stable operation over $100 \mathrm{~h}$ on stream. The outstanding performance of VPO is rationalized by its high activity in $\mathrm{HBr}$ oxidation and low propensity for methane and bromomethanes oxidation. Extrapolation to the oxybromination of ethane and propane over VPO suggested more complex reaction network in case of higher alkanes.
\end{abstract}

The emerging conventional and non-conventional natural-gas reserves - containing copious amounts of methane (75-99 mol.\%), but also ethane (1-15 mol.\%) and propane (110 mol.\%) - offer an exciting potential as a feedstock for value-added chemicals and fuels ${ }^{1-10}$. However, less than $10 \%$ of the global natural-gas production is currently used for the manufacture of commodities and the rest is burnt for heating, transport, and electricity generation purposes $^{1,2}$. This reflects the suboptimality of the state-of-the-art technologies for natural-gas upgrading, inevitably intermediated by energy- and capital- intensive reforming processes $^{1,2}$. Thus, more efficient methods allowing a selective one-step functionalization of the rather inert C-H bonds in methane and other alkanes have been recognized as 'El Dorado' in catalysis research. Among various strategies being proposed, halogen-based processes are particularly attractive as they enable a homolytic $\mathrm{C}-\mathrm{H}$ bond scission in the gas phase to 
proceed in a selective fashion under relatively mild conditions ( $T<800 \mathrm{~K}, P \sim 1$ bar, Fig. 1, left-middle) $)^{1,11,12}$. Bromination is preferred over chlorination as it provides high selectivity to mono-haloalkanes (also referred to as alkyl halides) and facile halogen elimination ${ }^{1}$ due to the weaker C-Br bond (284.9 $\mathrm{kJ} \mathrm{mol}^{-1}$ ) compared to C-Cl bond (338.9 kJ mol$\left.{ }^{-1}\right)$. Notably, both the bromination of the alkane and the subsequent dehydrobromination of bromoalkanes to a wide range of valuable products release $\mathrm{HBr}$ (Fig. 1, middle). The efficient recovery of bromine from the by-product $\mathrm{HBr}$ is a decisive factor to realize this approach at the industrial scale. The gas-phase oxidation of $\mathrm{HBr}$ over recently developed robust $\mathrm{RuO}_{2}, \mathrm{IrO}_{2}, \mathrm{CeO}_{2}$, or $\mathrm{TiO}_{2}$-based systems, generally proceeding at much lower temperatures compared to $\mathrm{HCl}$ oxidation, can be implemented as a separate step to close the bromine cycle ${ }^{13,14}$ (Fig. 1, top left). However, the integration of the alkane functionalization with the $\mathrm{HBr}$ recovery in a single step process via oxybromination reaction (Fig. 1, bottom left) is conceptually a more advanced strategy, as it enables process intensification and a theoretical $100 \%$ halogen atom efficiency $^{15-19}$. In fact, the oxyhalogenation of light alkanes, which has a long history dating back to the first half of the $20^{\text {th }}$ century ${ }^{20}$, has been forecasted as the most cost-effective technology for natural-gas upgrading ${ }^{1}$. Different materials such as noble Ru- and Rh-based catalysts, as well as non-noble $\mathrm{FePO}_{4}$ and $\mathrm{CeO}_{2}$ systems have been reported to catalyze the oxybromination of methane, which is typically claimed to proceed as a heterogeneouslycatalyzed reaction ${ }^{15-19}$. Besides the polybromination leading to $\mathrm{CH}_{2} \mathrm{Br}_{2}$ formation, $\mathrm{CO}_{x}$ generation is the main challenge in this reaction, eventually limiting the yield of the brominated products.

The present study aims at developing an oxybromination process for selective functionalization of methane through the symbiosis between heterogeneously-catalyzed $\mathrm{HBr}$ oxidation and gas-phase alkane bromination, sustained by the radicals continuously supplied from the bromine pool that is in turn regenerated on the catalyst surface by molecular oxygen. 
The $\mathrm{C}-\mathrm{H}$ bond scission is thus decoupled from the highly reactive oxygen species on the catalyst, which would generally promote the undesired deeper oxidation of alkane and brominated products. The key to accomplish this micro-level spatio-temporal management of the complex heterogeneous-gas-phase network is to find a catalyst which is able to oxidize $\mathrm{HBr}$, but is inert with respect to the $\mathrm{C}-\mathrm{H}$ bonds of the carbon containing molecules. Owing to their stability and operational window which generally coincides with that of the gas-phase alkane bromination (Fig. 1, left), the above-mentioned HBr oxidation catalysts ${ }^{13,14}$ are the interesting candidates to be applied in the oxybromination reaction, although their strong oxidizing character is likely to cause substantial combustion. These undesired oxidation reactions can be suppressed by applying the concept of redox site isolation through dispersion in a quasi-inert matrix such as phosphates, allowing better control of the surface-active oxygen species, as well as fine tuning of the redox and acid-base properties ${ }^{21,22}$. The phosphate incorporation also ensures that the redox centers are more stable under the highly corrosive oxybromination conditions ${ }^{23}$, while the involvement of lattice oxygen (Mars-van Krevelen mechanism) $)^{21,22}$ makes the oxidation less severe.

Herein, the catalytic activity of different oxides and phosphates in the oxybromination of methane was systematically investigated. A set of new active materials, comprising vanadium phosphate (VPO) as the flag-ship oxybromination catalyst, has been identified at ca. $100 \mathrm{~K}$ lower temperature compared to the previous reports ${ }^{15-19}$. Performance differences among various catalysts were related to their activities in the oxidation of $\mathrm{HBr}$, methane, and bromomethanes, which are proposed to constitute the key descriptors of the oxybromination potential. The mechanism of methane oxybromination over VPO, which involves heterogeneous $\mathrm{HBr}$ oxidation coupled with gas-phase methane bromination, was supported experimentally and, based on that, feed optimization strategies to maximize the $\mathrm{CH}_{3} \mathrm{Br}$ 
selectivity and productivity were discussed. Finally, the oxybromination of the more activated light alkanes such as ethane and propane over VPO was investigated.

\section{Results and discussion}

Oxybromination of methane over oxide and phosphate catalysts. The gas-phase oxybromination of methane over different families of catalysts was studied using a fixed-bed reactor set-up (Supplementary Fig. 1). The concept of oxybromination based on in situ coupling of the catalyzed $\mathrm{HBr}$ oxidation with the non-catalyzed gas-phase bromination was first approached through evaluating the representative $\mathrm{HBr}$ oxidation catalysts, $\mathrm{TiO}_{2}, \mathrm{RuO}_{2}$, and $\mathrm{CeO}_{2}$ in the oxybromination of methane. The catalytic tests revealed a substantial productivity of $\mathrm{CH}_{3} \mathrm{Br}$ and $\mathrm{CH}_{2} \mathrm{Br}_{2}$ over these materials, being significantly higher than the "background" activity of the empty quartz micro-reactor (Fig. 2). The highest yields of the brominated compounds were observed over $\mathrm{CeO}_{2}$, which was previously reported as an efficient oxybromination catalyst ${ }^{19} \cdot \mathrm{CH}_{2} \mathrm{Br}_{2}$ generation is a common challenge in both the bromination and oxybromination of methane, particularly if the mixture of bromomethanes is coupled to the higher hydrocarbons, where $\mathrm{CH}_{2} \mathrm{Br}_{2}$ is known to favor aromatics formation, eventually promoting the catalyst deactivation due to fouling ${ }^{6,24,25}$. Different strategies to convert $\mathrm{CH}_{2} \mathrm{Br}_{2}$ to methyl bromide and higher hydrocarbons via reprobromination ${ }^{24}$ or catalytic hydrodebromination reprocesses ${ }^{25}$, or acetic acid and its derivates ${ }^{15}$, make this product to be still utilized. Nevertheless, the selectivity to the bromomethanes over studied oxides was seriously conflicted by the $\mathrm{CO}_{2}$ generation, especially over $\mathrm{RuO}_{2}$ and $\mathrm{CeO}_{2}$. Although the $\mathrm{CO}_{x}$ formation might appear as an inherent drawback of the oxybromination approach, a substantial carbon loss also occurs in the oxygen free bromination of methane ${ }^{24}$ in the form of coke deposition, giving rise to a semi-continuous reactor operation. Among the two carbon oxides, $\mathrm{CO}_{2}$ is easier to separate, but the possibility to exploit $\mathrm{CO}$ as a 
carbonylation reagent in Monsanto-like process to yield acetic acid ${ }^{15}$ from $\mathrm{CH}_{3} \mathrm{Br}$ rises the overall efficiency of the carbon atom utilization. Thus, whilst a high yield of $\mathrm{CH}_{3} \mathrm{Br}$ is of prime interest, it is in first place necessary to suppress the undesirable $\mathrm{CO}_{2}$ formation, which is the only product of no practical use in the halogen-mediated light alkane upgrading chain. This is not possible over the above-mentioned oxide catalysts due to their strong oxidizing character related to high mobility of the surface oxygen atoms as well as high concentration of the basic oxygen sites ${ }^{26-29}$. The latter favors the nucleophilic attack on the brominated compounds, ultimately resulting in over-oxidation and combustion. To mitigate these, metal phosphates (Fig. 2, Supplementary Table 1) are promising candidates to reconceive mild oxidation potential with reduced oxygen basicity and high stability under the corrosive reaction environment ${ }^{18,21-23,30-34}$. The oxybromination tests performed over many phosphates have shown that besides the previously reported $\mathrm{FePO}_{4}$ catalyst ${ }^{18}, \mathrm{Cu}_{3}\left(\mathrm{PO}_{4}\right)_{2}, \mathrm{CrPO}_{4}$, and VPO, were highly active in this reaction. In fact, VPO provided the highest yield of the brominated compounds with negligible $\mathrm{CO}_{2}$ productivity and thus emerged out as the best catalyst among the all investigated systems. The X-ray diffraction (XRD) analysis of the VPO sample (Supplementary Fig. 2) evidenced the substantial bulk changes of the catalyst structure, primarily involving the reduction of the initial V(V) into V(IV) phases, although no changes in the catalyst performance could be observed (vide infra, Fig. 3).

The operational window of all active catalysts, including those which were previously reported to catalyze this reaction was advantageously shifted to at least $100 \mathrm{~K}$ lower temperatures as compared to the earlier works on the methane oxybromination ${ }^{15-19}$. This marked increase in activity is attributed to the absence of water inhibition when using dry $\mathrm{HBr}$ instead of its aqueous solution. The latter is commonly used in the studies reported to date. 
Evolution of the VPO structure in the oxybromination of methane. The VPO catalyst was evaluated in a long run followed by ex situ characterization of the samples recovered at different times in order to gain insights into structural alternations of the starting phase. Importantly, the conversion of methane as well as the product distribution remained unchanged over $100 \mathrm{~h}$ on stream (Fig. 3a). However, XRD analysis of the samples collected after quenching the reaction at 5, 15 and $40 \mathrm{~h}$ indicated a progressive transformation of the initial $\mathrm{VOPO}_{4}$ phases into a reduced $(\mathrm{VO})_{2} \mathrm{P}_{2} \mathrm{O}_{7}$ form (Fig. $\left.3 \mathbf{b}\right)$ and equilibration of the bulk phase composition within the first $15 \mathrm{~h}$ of the reaction. The reduction of the $\mathrm{V}^{5+}$ into $\mathrm{V}^{4+}$ was also evidenced by temperature-programmed reduction with hydrogen $\left(\mathrm{H}_{2}-\mathrm{TPR}\right)$ (Fig. 3c), and magic-angle spinning phosphorus-31 nuclear magnetic resonance ( ${ }^{31} \mathrm{P}$ MAS NMR) spectroscopy (Supplementary Fig. 3). The low-temperature peaks in the $\mathrm{H}_{2}$-TPR profiles positioned at $c a .780 \mathrm{~K}$ and $845 \mathrm{~K}$ are attributed to the reduction of $\mathrm{V}^{5+}$ species into $\mathrm{V}^{4+}$ and $\mathrm{V}^{3+}$, respectively ${ }^{35}$. These peaks gradually vanished over the reaction time and were almost not detectable in the $40 \mathrm{~h}$ sample. Similarly, the strong signals located around $\delta=0 \mathrm{ppm}$ in the ${ }^{31} \mathrm{P}$, which are characteristic to the $\mathrm{V}^{5+}$ states in $\mathrm{VOPO}_{4}$ phases ${ }^{36,37}$ were substantially reduced over time. Nevertheless, NMR spectra demonstrated the presence of small amount of $\mathrm{V}^{+5}$ even after $40 \mathrm{~h}$ on stream. An increase in crystallinity over reaction time was observed from XRD, ${ }^{31} \mathrm{P}$ MAS NMR, and high-resolution transmission electron microscopy (HRTEM) (Fig. 3b, Supplementary Fig. 3, 4) analyses and is corroborated with a decrease of the total surface area of the spent catalyst samples (Fig. 3b). Moreover, HRTEM evidenced a transformation of the needle-like (fresh) shaped particles into cuboids (40 h), and continuous presence of the amorphous layer on the surface of the crystalline grains. This layer was also observed in the $n$-butane oxidation to maleic anhydride over VPO catalysts and is thought to be crucial for the performance of VPO in this reaction ${ }^{38}$. More detailed picture on the nature of the active site needs further investigation, which is beyond the scope of this manuscript. 
Performance descriptors for the oxybromination catalyst. To rationalize the performance differences of various catalyst classes, we have studied their behavior in the reactions which are proposed to constitute the key descriptors for the ultimate product distribution in the oxybromination of methane (Fig. 4). These include the $\mathrm{HBr}$ oxidation, which is essential to enable a continuous (re)generation of bromine along the catalyst bed, and the combustion of the brominated products $\left(\mathrm{CH}_{3} \mathrm{Br}\right.$ and $\left.\mathrm{CH}_{2} \mathrm{Br}_{2}\right)$ and methane, being responsible for the loss in the overall selectivity to the brominated methanes. Temperatures at which $40 \%\left(T_{40}\right)$ of $\mathrm{HBr}$, $\mathrm{CH}_{3} \mathrm{Br}$, and $\mathrm{CH}_{2} \mathrm{Br}_{2}$, and $2 \%\left(T_{2}\right)$ of methane was converted were taken as the relative measure of the catalyst activity in the corresponding oxidation reactions. Based on the simple optimality criteria stating that a superior oxybromination catalyst should lead to the high rates of $\mathrm{HBr}$ oxidation with no combustion of methane or bromomethanes to ensure the high yields of the later, the relative activities of the catalysts were cross-compared by plotting them along the edges of the catalytic pyramid (Fig. 4). From this presentation, the outstanding oxybromination performance of the VPO can be rationalized by its high activity in the $\mathrm{HBr}$ oxidation, which is comparable to those of $\mathrm{CeO}_{2}$ and $\mathrm{TiO}_{2}$, and relatively low combustion activity, making this catalyst closest to the apex of the pyramid.

Heterogeneous-gas-phase reaction pathways over VPO. The study of performance descriptors (vide supra) evidenced that the oxidation of methane over $\mathrm{VPO}$ and $\mathrm{FePO}_{4}$ under conditions similar to those applied in the oxybromination reaction is rather slow (Fig. 4). This points to a high activation barrier for the catalytic C-H bond scission and hints that the gasphase bromination to be a likely pathway for $\mathrm{C}-\mathrm{Br}$ bond formation in the oxybromination reaction. To verify this aspect following experiments were conducted. First gas-phase bromination was performed over a bed of inert quartz particles having the volume of a typical 
catalyst bed in the oxybromination of methane (Fig. 5a). The results demonstrated that the onset temperature of $c a .675 \mathrm{~K}$, as well as trends in methane conversion and distribution of the brominated products in the bromination reaction are in a good agreement with those in the oxybromination reaction (Fig. 5a, vide infra Fig 6a). The only exception was $\mathrm{CO}$ formation in the latter process. Addition of the molecular oxygen to the bromination mixture (Fig. 5a) did not change the product yields, except at $754 \mathrm{~K}$ where some CO is observed, testifying the absence of any inhibition by $\mathrm{O}_{2}$. This pronounced difference in $\mathrm{CO}$ productivity suggests that its formation in the oxybromination reaction likely originates from the combustion of brominated products on the catalysts, which is also reflected by lower $T_{40}$ for $\mathrm{CH}_{3} \mathrm{Br}$ and $\mathrm{CH}_{2} \mathrm{Br}_{2}$ combustion over catalysts compared to that over inert SiC particles (Fig. 4). Secondly, the quantification of the molecular bromine during the oxybromination over VPO showed that this was the main product observed at low temperatures (ca. 88\% yield at 90\% HBr conversion) (Fig. 5b), suggesting the bromine desorption to occur at low temperatures. When rising the bed temperature, the increasing productivity of the bromomethanes is accompanied with decreasing bromine yield and $\mathrm{HBr}$ conversion, pointing out the uptake of the evolved bromine by methane in the gas phase resulting in $\mathrm{HBr}$ liberation. These evidences unambiguously suggest that the formation of $\mathrm{C}-\mathrm{Br}$ bonds in methane oxybromination originates from by the gas-phase reaction between methane and bromine. To comprehend whether the gas-phase free radical chain reactions can be unfolded in our experimental conditions, we simulated the bromination of methane under conditions comparable to those applied in the oxybromination (Supplementary Fig. 5), which revealed that significant methane conversion and yields of brominated products can be reached at the residence times estimated for the void volume between the catalyst particles.-Based on this consideration, a simplified reaction mechanism was proposed for VPO. The bromine that is formed by the catalytic $\mathrm{HBr}$ oxidation (Eq. 1) initiates the gas-phase bromination (Eq. 2) and 
polybromination (Eq. 3) reactions, liberating the $\mathrm{HBr}$ which is continuously recycled on the catalyst surface (Eq. 1). The functionalized bromomethanes are more prone to oxidize than methane (Eq. 4), leading to $\mathrm{CO}_{x}$ formation, which predominantly occurs on the catalyst surface.

$2 \mathrm{HBr}+0.5 \mathrm{O}_{2} \rightarrow \mathrm{Br}_{2}+\mathrm{H}_{2} \mathrm{O}$

$\mathrm{CH}_{4}+\mathrm{Br}_{2} \rightarrow \mathrm{CH}_{3} \mathrm{Br}+\mathrm{HBr} \quad$ Eq. 2

$\mathrm{CH}_{3} \mathrm{Br}+\mathrm{Br}_{2} \rightarrow \mathrm{CH}_{2} \mathrm{Br}_{2}+\mathrm{HBr}$

$\mathrm{CH}_{4-x} \mathrm{Br}_{x}+0.5(2-x+y) \mathrm{O}_{2} \rightarrow \mathrm{CO}_{y}+x \mathrm{HBr}+(2-x) \mathrm{H}_{2} \mathrm{O} \quad$ Eq. 4

Improved productivity by optimizing the operating conditions. Having rationalized the performance of the best catalyst, VPO, and understood the different pathways of oxybromination, our next step was to improve the $\mathrm{CH}_{3} \mathrm{Br}$ selectivity by engineering the feed compositions and reaction conditions. Partial pressure of oxygen is critical as it is expected to promote the undesired oxybromination reactions. Moreover, it was demonstrated that the present oxygen content is sufficient to attain high $\mathrm{HBr}$ conversions (Fig. 5b). Based on our findings that the gas-phase methane bromination is the principal pathway of methane activation over VPO catalyst and well-known kinetics of the bromination reaction ${ }^{4-6,24,39}$, a methane-rich feed is expected to enhance the selectivity towards $\mathrm{CH}_{3} \mathrm{Br}$, by reducing polybromination. Indeed, an increase of the methane concentration in the inlet feed from ca. 4.5 to 10 vol.\% brought to $\mathrm{ca}$. double increase of the $\mathrm{CH}_{3} \mathrm{Br}$ productivity and $10 \%$ increase in its selectivity at $753 \mathrm{~K}$ (Fig. 5c). By decreasing the bed temperature to $693 \mathrm{~K}$, the space time yield of $\mathrm{CH}_{3} \mathrm{Br}$ at 10 vol.\% of $\mathrm{CH}_{4}$ in the inlet feed was similar to that obtained with 4.5 vol.\% methane feed content at $60 \mathrm{~K}$ higher temperature. Importantly, the selectivity to $\mathrm{CH}_{3} \mathrm{Br}$ reached $91 \%$, with $\mathrm{ca}$. $5 \%$, and $4 \%$ selectivity to $\mathrm{CO}$ and $\mathrm{CH}_{2} \mathrm{Br}_{2}$, respectively. An increase in the total pressure from 1.4 to 1.8 bar led to an increase in the methane conversion. 
Nevertheless, the Pareto-like dependence of the selectivity to $\mathrm{CH}_{3} \mathrm{Br}$ on $\mathrm{CH}_{4}$ was preserved. To further verify the applicability of the VPO under realistic, reactant-reach feeds, its performance was evaluated at increasing partial pressures of the reactants, while keeping their molar ratio constant (Fig. 5d). Little alternations in the product distribution at similar methane conversions that were thus observed demonstrate the scalability of catalyst performance, and consequentially, a strong enhancement of the space time yield of methyl bromide.

Extrapolation to other light alkanes. The applicability of the VPO catalyst for the functionalization of other two representative alkane candidates, ethane and propane, was further explored (Fig. 6). The onset temperature of the oxybromination reaction increased in the order: propane $<$ ethane $<$ methane, in line with increase in their C-H bond strengths ${ }^{41}$. In case of methane, a high selectivity to $\mathrm{CH}_{3} \mathrm{Br}$ (>92\%) can be achieved at low conversions ( $<7 \%)$. However, further increase of conversion, which obeys a linear dependence on the temperature, was inevitably coupled with a loss in the selectivity to $\mathrm{CH}_{3} \mathrm{Br}$ (vide supra) due to $\mathrm{CH}_{2} \mathrm{Br}_{2}$ and $\mathrm{CO}$ formation. Likewise, in the oxybromination of ethane, bromoethane $\left(\mathrm{C}_{2} \mathrm{H}_{5} \mathrm{Br}\right)$ was the principal product in the lower temperature window (83\% selectivity, 8\% conversion), but in contrast to methane, no polybrominated ethanes could be detected at the reactor outlet. This might be due to their susceptibility to cracking and/or combustion, which can also explain the equimolar production of $\mathrm{CO}$ and $\mathrm{CH}_{4}$ at higher conversions, where the polybromination is more favored. Interestingly, the selectivity to the latter C1 products was slightly decreased at higher temperature. Instead, a drop in selectivity to $\mathrm{C}_{2} \mathrm{H}_{5} \mathrm{Br}$ was progressively compensated with the ethylene $\left(\mathrm{C}_{2} \mathrm{H}_{4}\right)$ formation, suggesting the in-situ dehydrobromination of the former, which can be promoted over phosphate catalysts ${ }^{23}$. The productivity of $\mathrm{C}_{2} \mathrm{H}_{4}$ (67\% selectivity, $42 \%$ conversion) was higher than that observed in the 
oxidative dehydrogenation of ethane over VPO conducted under comparable conditions (Supplementary Fig. 6), and those previously reported for the best performing VPO systems in the oxidative dehydrogenation ${ }^{41}$. The rate of double bond formation in case of propane $\left(\mathrm{C}_{3} \mathrm{H}_{8}\right)$ was also higher than that recorded in the oxidative dehydrobromination performed under similar conditions (Fig. 6). Nevertheless, given the even weaker C-C bonds in propyl radicals ${ }^{40,42}$, cracking reactions were more pronounced than in ethane, resulting in $\mathrm{C}_{2} \mathrm{H}_{5} \mathrm{Br}$ to be a dominant product in the lower temperature window, while no bromopropanes could be detected. Moreover, at higher temperatures coking was evidenced from a substantial deviation in the carbon balance (vide infra $10 \%$ at $693 \mathrm{~K}$ ) and visually confirmed by the dark deposits on the catalyst bed and reactor wall. The results on ethane and propane suggest even more complex reaction network as compared to methane, likely induced by the higher affinity of higher alkanes and the corresponding bromoalkanes to the catalyst surface. Although challenging from the point of the catalyst and process design, they testify the bright perspective of the oxybromination approach to functionalize light alkanes.

\section{Conclusions and outlook}

Our efforts to design a catalyst allowing synergetic interaction between the heterogeneous $\mathrm{HBr}$ oxidation and gas-phase methane bromination resulted in identification of vanadium phosphate, providing the highest yields of the bromomethanes, along with negligible $\mathrm{CO}_{2}$ production. The catalyst demonstrated a stable operation over $100 \mathrm{~h}$ on stream, despite the restructuring of its bulk, which was equilibrated within the first $15 \mathrm{~h}$ of reaction. The outstanding performance of VPO was rationalized by its high activity in the $\mathrm{HBr}$ oxidation and low propensity to oxidize methane and brominated compounds. Based on the mechanistic understanding of the reaction comprising synergetic cooperation between the heterogeneous $\mathrm{HBr}$ oxidation and gas-phase methane bromination, the productivity of $\mathrm{CH}_{3} \mathrm{Br}$ over VPO 
catalyst was further enhanced by optimizing the reaction conditions, where the selectivity to $\mathrm{CH}_{3} \mathrm{Br}$ above $90 \%$ was attained by increasing the feed partial pressure of methane. The oxybromination of ethane and propane over VPO indicated a more complex reaction network, comprising dehydrobromination, but also cracking of the brominated compounds. In case of ethane, high yields of ethylene could be achieved, with only marginal $\mathrm{CO}_{2}$ formation. These findings constitute an important step and provide a comprehensive background for the design of an efficient process to valorize the abundant and readily available natural-gas reserves.

\section{Methods}

Catalyst preparation. $\mathrm{TiO}_{2}$-rutile (Aldrich, nanopowder, 99.5\%) and $\mathrm{Cu}_{3}\left(\mathrm{PO}_{4}\right)_{2}(\mathrm{ABCR}$, 98\%), $\mathrm{RuO}_{2}$ (Sigma Aldrich, $99.9 \%$ ) and $\mathrm{CeO}_{2}$ (Sigma Aldrich, 99.9\%) were calcined at 823, 723 and $1173 \mathrm{~K}$, respectively, in static air with a heating rate of $5 \mathrm{~K} \mathrm{~min}^{-1}$ for $5 \mathrm{~h}$. Vanadium phosphate (VPO) was prepared via an organic route ${ }^{22}$. A suspension of $\mathrm{V}_{2} \mathrm{O}_{5}$ (15 g, Aldrich, $\geq 99.6 \%)$ in isobutanol (90 $\mathrm{cm}^{3}$, Acros, > 99\%) and benzyl alcohol $\left(60 \mathrm{~cm}^{3}\right.$, Sigma Aldrich, > 99\%) was refluxed for $3 \mathrm{~h}$. After cooling down to room temperature, $\mathrm{H}_{3} \mathrm{PO}_{4}$ (Sigma Aldrich, $\geq 85 \%$ ) was added to set the molar P/V ratio to 1.2 and the mixture was then refluxed for another $16 \mathrm{~h}$. The resulting slurry was separated by filtration, washed with isobutanol and methanol (Fluka, $\geq 99.9 \%$ ), dried in vacuum (50 mbar) at $373 \mathrm{~K}$ for $16 \mathrm{~h}$, and finally activated in flowing air $\left(100 \mathrm{~cm}^{3} \mathrm{STP} \mathrm{min}^{-1}\right)$ at $823 \mathrm{~K} \mathrm{~min}^{-1}\left(5 \mathrm{~K} \mathrm{~min}^{-1}\right)$ for $5 \mathrm{~h}$. $\mathrm{FePO}_{4}$ was prepared by mixing the $\mathrm{Fe}\left(\mathrm{NO}_{3}\right)_{3} \cdot 9 \mathrm{H}_{2} \mathrm{O}(13.38 \mathrm{~g}$, Sigma Aldrich, $\geq 98 \%)$ and $\left(\mathrm{NH}_{4}\right) \mathrm{H}_{2} \mathrm{PO}_{4}$ (3.81 g, Acros, > 99\%) in deionized water for $2 \mathrm{~h}$, followed by drying in vacuum (50 mbar) at $363 \mathrm{~K}$ for $16 \mathrm{~h}$ and calcination in flowing air $\left(100 \mathrm{~cm}^{3} \mathrm{STP} \mathrm{min}^{-1}\right)$ at $873 \mathrm{~K}\left(5 \mathrm{~K} \mathrm{~min}^{-1}\right)$ for $5 \mathrm{~h}$. $\mathrm{CrPO}_{4}$ was synthesized by mixing aqueous $\mathrm{CrCl}_{3} \cdot 6 \mathrm{H}_{2} \mathrm{O}(0.09 \mathrm{M}$, $1 \mathrm{dm}^{3}$, Aldrich, $\left.\geq 98 \%\right)$ and $\mathrm{KH}_{2} \mathrm{PO}_{4}\left(0.09 \mathrm{M}, 1 \mathrm{dm}^{3}\right.$, Fluka, $\left.\geq 99.5 \%\right)$ in deionized water with 
$\mathrm{NaCH}_{3} \mathrm{COO} \cdot 3 \mathrm{H}_{2} \mathrm{O}(0.1 \mathrm{M}$, Acros, > 99\%) for $6 \mathrm{~h}$. The precipitate was recovered by filtration, washed with water, dried in vacuum (50 mbar) at $363 \mathrm{~K}$ for $3 \mathrm{~h}$, and finally calcined in flowing air $\left(100 \mathrm{~cm}^{3} \mathrm{STP} \mathrm{min}^{-1}\right)$ at $1273 \mathrm{~K}\left(20 \mathrm{~K} \mathrm{~min}^{-1}\right)$ for $3 \mathrm{~h}$. The preparation of other metal phosphates, $\mathrm{CePO}_{4}, \mathrm{LaPO}_{4}, \mathrm{Ti}_{2} \mathrm{P}_{2} \mathrm{O}_{7}, \mathrm{Mn}_{3}\left(\mathrm{PO}_{4}\right)_{2}, \mathrm{CoPO}_{4}, \mathrm{Ni}_{3}\left(\mathrm{PO}_{4}\right)_{2}$, and $\mathrm{Zn}_{3}\left(\mathrm{PO}_{4}\right)_{2}$, studied in this work is provided in the Supplementary information.

Catalyst characterization. Powder XRD was measured using PANalytical X'Pert PROMPD diffractometer. Data were recorded in the $10-70^{\circ} 2 \theta$ range with an angular step size of $0.017^{\circ}$ and a continuing time of 0.26 s per step. $\mathrm{N}_{2}$ sorption at $77 \mathrm{~K}$ was performed using a Quantachrome Quadrosorb-SI analyzer. Prior to the measurement, the solid was evacuated to 50 mbar at $573 \mathrm{~K}$ for $12 \mathrm{~h}$. $\mathrm{H}_{2}$-TPR was measured using a Micromeritics Autochem 2920 unit. The sieved sample (40 mg) was loaded into a U shaped quartz microreactor and pretreated in He $\left(20 \mathrm{~cm}^{3} \mathrm{STP} \mathrm{min}^{-1}\right)$ at $473 \mathrm{~K}$ for $30 \mathrm{~min}$. The analysis was carried out in $5 \mathrm{vol} . \% \mathrm{H}_{2} / \mathrm{Ar}\left(20 \mathrm{~cm}^{3} \mathrm{STP} \mathrm{min}^{-1}\right)$, ramping the temperature from 473 to $1203 \mathrm{~K}$ at $10 \mathrm{~K} \mathrm{~min}^{-1}$. The ${ }^{31} \mathrm{P}$ MAS NMR spectra were recorded at a spinning speed of $80 \mathrm{kHz}$ by using a Bruker Avance 400 NMR spectrometer at $400 \mathrm{MHz}$ and 9.4 T. The spectra were recorded by using 512 accumulations at 8 ms pulses and a relaxation time of 1 s, with $85 \%$ $\mathrm{H}_{3} \mathrm{PO}_{4}$ as a reference. HRTEM measurements were performed using a FEI Tecnai F30 ST microscope (field emission gun, operated at $300 \mathrm{kV}$ ).

Catalyst testing. Oxybromination of alkanes was performed in a home-made continuousflow micro reactor (See Supplementary Fig. 1). The catalyst $\left(W_{\text {cat }}=1 \mathrm{~g}\right.$, particle size $d_{\mathrm{P}}=0.4-0.6 \mathrm{~mm}$ ) was loaded in a quartz tube (16 mm internal diameter) over a plug of quartz wool and pretreated in He flow for 30 min prior to the reaction. Unless otherwise stated, steady-state tests were conducted at a total pressure $(P)$ of 1.4 bar in a temperature $\left(T_{\text {bed }}\right)$ 
range of 673-773 K using a total flow $\left(F_{\mathrm{T}}\right)$ of $100 \mathrm{~cm}^{3}$ STP $\mathrm{min}^{-1}$ consisting of $4.5 \mathrm{vol} . \%$ methane, ethane, or propane (Messer, 20\% in He), 1.5 vol.\% $\mathrm{O}_{2}$ (PanGas, 5\% in $\mathrm{He}$ ), 3 vol.\% $\mathrm{HBr}$ (Messer, 2.3 anhydrous), and 3 vol.\% Ar (PanGas, purity 5.0) balanced in He (PanGas, purity 5.0). In combustion tests, $\mathrm{CH}_{3} \mathrm{Br}$, synthesized in the laboratory, was supplied by a mass flow controller and $\mathrm{CH}_{2} \mathrm{Br}_{2}$ (ABCR, 99\%) was fed with a syringe pump into a homemade evaporator using the feed gas (mixture of $\mathrm{O}_{2}$, He, and $\mathrm{Ar}, 100 \mathrm{~cm}^{3} \mathrm{STP} \mathrm{min}^{-1}$ ) as carrier. The bromination of methane was performed over a bed of quartz particles (particle size $d_{\mathrm{P}}=0.4-0.6 \mathrm{~mm}$ ) at 1.55 bar using a feed containing 4.5 vol. $\% \mathrm{CH}_{4}, 1.5$ vol. $\% \mathrm{Br}_{2}$ (Acros, > 99.8\%), 0 or 1.5 vol.\% $\mathrm{O}_{2}$, and 3 vol.\% Ar balanced in He. Liquid $\mathrm{Br}_{2}$ was supplied by means of syringe pump and directly evaporated into the remaining gas mixture in a homemade evaporator. The effluent gas stream was analyzed after $1 \mathrm{~h}$ of stabilization under each reaction condition. The $\mathrm{Br}_{2}$ content was determined off-line by iodometric titration using Mettler Toledo G20 Compact Titrator. The amount of the carbon-containing products (methane, ethane, propane, ethylene, propylene, their brominated derivatives, $\mathrm{CO}$, and $\mathrm{CO}_{2}$ ) and $\mathrm{HBr}$ in the effluent gas was determined with a gas chromatograph equipped with GSCarbonPLOT column (113-3133) coupled to a mass spectrometer (GC-MS, Agilent GC 6890, MS 5973N). The HBr oxidation was performed in a continuous-flow setup as described elsewhere ${ }^{13}$. Further experimental details with respect to the product analyses are given in the Supplementary information.

\section{Acknowledgements}

The authors acknowledge financial support from the Swiss National Science Foundation (project no. 200021-156107). The Scientific Center for Optical and Electron Microscopy (ScopeM) at ETH Zurich is thanked for providing the access to the facility. Zhen Guo is 
acknowledged for assistance with catalyst preparation. The authors are grateful to Frank Krumeich for HRTEM analyses and René Verel for ${ }^{31} \mathrm{P}$ MAS NMR analyses.

\section{Author contributions}

J.P.-R. conceived and coordinated all stages of this research. V.P. prepared the catalyst samples, performed the catalytic tests, and characterized materials by XRD and $\mathrm{H}_{2}-\mathrm{TPR}, \mathrm{G} . \mathrm{Z}$. and M.M. conducted part of the catalytic tests. A.P.A. assisted in HRTEM and solid-state NMR characterization. V.P., M.M., A.P.A., and J.P.-R. wrote the paper. Correspondence and requests for materials should be addressed to J.P.-R.

\section{Competing financial interests}

The authors declare that they have no competing financial interests.

\section{References}

1. McFarland, E. Unconventional chemistry for unconventional natural gas. Science 338, 340-342 (2012).

2. Horn, R. \& Schlögl, R. Methane activation by heterogeneous catalysis. Catal. Lett. 145, 23-39 (2015).

3. Hammer, G. et al. in Ullmann's Encyclopedia of Industrial Chemistry Vol. 23, pp. 739792 (Wiley-VCH, Weinheim, 2012).

4. Zhou, X. P. et al. Integrated process for synthesizing alcohols and ethers from alkanes. United States patent US6472572 B1 (2002).

5. Zhou, X.-P. et al. An integrated process for partial oxidation of alkanes. Chem. Commun. 2294-2295 (2003). 
6. Lorkovic, I. M. et al. C1 coupling via bromine activation and tandem catalytic condensation and neutralization over CaO/zeolite composites. Chem. Commun. 566-567 (2004).

7. Breed, A. et al. Natural gas conversion to liquid fuels in a zone reactor. Catal. Today 106, 301-304 (2005).

8. Svelle, S. et al. The methyl halide to hydrocarbon reaction over H-SAPO-34. J. Catal. 241, 243-254 (2006).

9. Osterwalder, N. \& Stark, W. J. Direct coupling of bromine-mediated methane activation and carbon-deposit gasification. ChemPhysChem 8, 297-303 (2007).

10. Ding, K., Metiu, H. \& Stucky, G. D. Interplay between bromine and iodine in oxidative dehydrogenation. ChemCatChem 5, 1906-1910 (2013).

11. Olah, G. A. \& Molnár, Á. in Hydrocarbon Chemistry Ch. 10.2 (John Wiley \& Sons, Inc. Hoboken, 2003).

12. Olah, G. A., Goeppert, A. \& Prakash, G. K. S. in Beyond Oil and Gas: The Methanol Economy Ch. 12.3.4 (Wiley-VCH, Weinheim, 2009).

13. Moser, M., Rodríguez-García, L., Amrute, A. P. \& Pérez-Ramírez, J. Catalytic bromine recovery: an enabling technology for emerging alkane functionalization processes. ChemCatChem 5, 3520-3523 (2013).

14. Moser, M., Czekaj, I., López, N. \& Pérez-Ramírez, J. The virtue of defects: stable bromine production by catalytic oxidation of hydrogen bromide on titanium oxide. Angew. Chem. Int. Ed. 53, 8628-8633 (2014).

15. Wang, K. X., Xu, H. F., Li, W. S. \& Zhou, X. P. Acetic acid synthesis from methane by non-synthesis gas process. J. Mol. Catal. A: Chem. 225, 65-69 (2005).

16. Liu, Z. et al. Higher hydrocarbons from methane condensation mediated by HBr. J. Mol. Catal. A: Chem. 273, 14-20 (2007). 
17. Yang, F., Liu, Z., Li, W. S., Wu. T. H. \& Zhou, X. P. The oxidative bromination of methane over $\mathrm{Rh} / \mathrm{SiO}_{2}$ catalysts. Catal. Lett. 124, 226-232 (2008).

18. Lin, R. et al. Efficient and stable silica-supported iron phosphate catalysts for oxidative bromination of methane. J. Catal. 272, 65-73 (2010).

19. He, J. et al. Transformation of methane to propylene: a two-step reaction route catalyzed by modified $\mathrm{CeO}_{2}$ nanocrystals and zeolites. Angew. Chem. Int. Ed. 51, 2438-2442 (2012).

20. Gorin, E. Hydrocarbon conversion process. United States patent US2407828 (1946).

21. Albonetti, S., Cavani, F. \& Trifirò, F. Key aspects of catalyst design for the selective oxidation of paraffins. Catal. Rev. -Sci. Eng. 38, 413-438 (1996).

22. Schlögl, R. in Modern Heterogeneous Oxidation Catalysis: Design, Reactions and Characterization Ch. 1, pp. 1-42 (Wiley-VCH, Weinheim, 2009).

23. Carroll, R. T., De Witt, E. J., Falls, C. \& Trapasso, L. E. Oxychlorination of lower alkanes. United States patent US3173962 (1965).

24. Gadewar, S. et al. Continuous process for converting natural gas to liquid hydrocarbons. United States patent US20100096588 A1 (2010).

25. Ding, K. et al. Hydrodebromination and oligomerization of dibromomethane. ACS Catal. 2, 479-486 (2012).

26. Martin, D. \& Duprez, D. Mobility of surface species on oxides. 1. Isotopic exchange of ${ }^{18} \mathrm{O}_{2}$ with ${ }^{16} \mathrm{O}$ of $\mathrm{SiO}_{2}, \mathrm{Al}_{2} \mathrm{O}_{3}, \mathrm{ZrO}_{2}, \mathrm{MgO}, \mathrm{CeO}_{2}$, and $\mathrm{CeO}_{2}-\mathrm{Al}_{2} \mathrm{O}_{3}$. Activation by noble metals. Correlation with oxide basicity. J. Phys. Chem. 100, 9429-9438 (1996).

27. Ferretto, L. \& Glisenti, A. Surface acidity and basicity of a rutile powder. Chem. Mater. 15, 1181-1188 (2003). 
28. Hevia, M. A. G., Amrute, A. P., Schmidt, T. \& Pérez-Ramírez, J. Transient mechanistic study of the gas-phase $\mathrm{HCl}$ oxidation to $\mathrm{Cl}_{2}$ on bulk and supported $\mathrm{RuO}_{2}$ catalysts. $J$. Catal. 276, 141-151 (2010).

29. Chen, C.-Y. \& Pignatello, J. J. Catalytic oxidation for elimination of methyl bromide fumigation emissions using ceria-based catalysts. Appl. Catal. B 142-143, 785-794 (2013).

30. Ai, M. \& Ohdan, K. Oxidation by iron phosphate catalyst. J. Mol. Catal. A: Chem.159, 19-24 (2000).

31. Bautista, F. M. et al. Effect of precipitation medium on surface acidity and catalytic performance of chromium orthophosphates in cyclohexene skeletal isomerization and cumene conversion. J. Mater. Chem. 3, 975-978 (1993).

32. Busca, G., Cavani, F., Centi, G. \& Trifirò, F. Nature and mechanism of formation of vanadyl pyrophosphate: active phase in $n$-butane selective oxidation. J. Catal. 99, 400414 (1986).

33. Hutchings, G. J., Desmartin-Chomel, A., Olier, R. \& Volta, J.-C. Role of the product in the transformation of a catalyst to its active state. Nature 368, 41-45 (1994).

34. Coulston, G. W. et al. The kinetic significance of $\mathrm{V}^{5+}$ in $n$-butane oxidation catalyzed by vanadium phosphates. Science 275, 191-193 (1997).

35. Mahdavi, V. \& Hasheminasab, H. R. Vanadium phosphorous oxide catalyst promoted by cobalt doping for mild oxidation of benzyl alcohol to benzaldehyde in the liquid phase. Appl. Catal. A 482, 189-197 (2014).

36. Aït-Lachgar, K. et al. Selective oxidation of $n$-butane to maleic anhydride on vanadyl pyrophosphate. II. Characterization of the oxygen-treated catalyst by electrical conductivity, Raman, XPS, and NMR spectroscopic techniques. J. Catal. 177, 224-230 (1998). 
37. Frey, J. et al. Vanadium phosphates on mesoporous supports: model catalysts for solidstate NMR studies of the selective oxidation of $n$-butane. Solid State Nucl. Magn. Reson. 35, 130-137 (2009).

38. Hutchings, G. J. Vanadium phosphate: a new look at the active components of catalysts for the oxidation of butane to maleic anhydride. J. Mater. Chem.14, 3385-3395 (2004).

39. Kistiakowsky, G. B. \& Van Artsdalen, E. R. Bromination of hydrocarbons. I. Photochemical and thermal bromination of methane and methyl bromide. Carbonhydrogen bond strength in methane. J. Chem. Phys. 12, 469-478 (1944).

40. Luo, Y.-R. in Comprehensive Handbook of Chemical Bond Energies. Chs. 3.1 and 4.1 (Taylor \& Francis Group, Boca Raton, 2007).

41. Cavani, F., Ballarini, N. \& Cericola, A. Oxidative dehydrogenation of ethane and propane: how far from commercial implementation. Catal. Today 127, 113-131 (2007).

42. Tsang, W. The stability of alkyl radicals. J. Am. Chem. Soc. 107, 2872-2880 (1985). 


\section{Figure legends}

Figure 1 | Closed loop bromine-mediated light alkane conversion scheme to produce value-added chemicals and fuels. This route, entailing the bromination of alkane coupled to the oxidation of the $\mathrm{HBr}$ by-product to recover bromine, is highly attractive to capitalize on abundant reserves of conventional and unconventional natural gas as chemical feedstock. Alkane oxybromination enables the integration of bromination and oxidation steps, ultimately leading to process intensification.

Figure 2 | Catalytic performance expressed as single-pass carbon yields $(Y)$ of products for selected catalysts in the oxybromination of methane at $753 \mathrm{~K}$. The superiority of vanadium phosphate with respect to oxides and other phosphate catalysts is characterized by the highest yield to $\mathrm{CH}_{3} \mathrm{Br}$ with negligible $\mathrm{CO}_{2}$ formation. The vertical dashed line serves as an eye guide to compare $\mathrm{CH}_{3} \mathrm{Br}$ yields. The estimated experimental errors are indicated in the Supplementary Table 1. Other reaction conditions are provided in Methods.

Figure 3 | Evolution of vanadium phosphate in the oxybromination of methane at $753 \mathrm{~K}$.

a) The conversion of methane $(X)$ and selectivity $(S)$ to different reaction products remained unaltered during $100 \mathrm{~h}$ on stream over VPO highlighting its stable performance. b, c) Characterization of VPO samples collected after different reaction times by XRD, total surface area $\left(S_{\mathrm{BET}}\right)$, and $\mathrm{H}_{2}$-TPR showed the gradual stabilization of the original vanadium oxyphosphate $\left(\mathrm{VOPO}_{4}\right)$ into reduced pyrophosphate $\left((\mathrm{VO})_{2} \mathrm{P}_{2} \mathrm{O}_{7}\right)$ form during the catalytic run. Nevertheless, it had no impact on the overall catalyst activity. Other conditions are described in Methods.

Figure 4 | Performance descriptors for the design of selective methane oxybromination catalyst. The optimal catalytic material should sit at the apex of the pyramid. 
Temperatures at which $40 \%\left(T_{40}\right)$ of $\mathrm{HBr}, \mathrm{CH}_{3} \mathrm{Br}$, and $\mathrm{CH}_{2} \mathrm{Br}_{2}$, or $2 \%\left(T_{2}\right)$ of methane is converted are taken as a relative measure of the catalysts' activity in the corresponding oxidation reactions (activity profiles are shown at the respective corner of the pyramid). Conditions: $\mathrm{HBr}$ oxidation: $W_{\text {cat }}=0.25 \mathrm{~g}, P=1 \mathrm{bar}, F_{\mathrm{T}}=166 \mathrm{~cm}^{3} \mathrm{STP} \mathrm{min}^{-1}$ containing 10 vol. $\% \mathrm{HBr}$ and 20 vol.\% $\mathrm{O}_{2}$ balanced in $\mathrm{He} ; \mathrm{CH}_{3} \mathrm{Br}$ oxidation: $W_{\text {cat }}=1.0 \mathrm{~g}, P=1.4$ bar, $F_{\mathrm{T}}=100 \mathrm{~cm}^{3} \mathrm{STP} \mathrm{min}^{-1}$ containing 1 vol.\% $\mathrm{CH}_{3} \mathrm{Br}$ and 1.5 vol.\% $\mathrm{O}_{2}$ balanced in $\mathrm{He} ; \mathrm{CH}_{2} \mathrm{Br}_{2}$ oxidation: $W_{\text {cat }}=1.0 \mathrm{~g}, P=1.4 \mathrm{bar}, F_{\mathrm{T}}=100 \mathrm{~cm}^{3} \mathrm{STP} \min ^{-1}$ containing 1 vol. $\% \mathrm{CH}_{2} \mathrm{Br}_{2}$ and 1.5 vol.\% $\mathrm{O}_{2}$ balanced in $\mathrm{He}$; $\mathrm{CH}_{4}$ oxidation: $W_{\text {cat }}=1.0 \mathrm{~g}, P=1.4 \mathrm{bar}$, $F_{\mathrm{T}}=100 \mathrm{~cm}^{3} \mathrm{STP} \mathrm{min}^{-1}$ containing 4.5 vol.\% $\mathrm{CH}_{4}$ and 1.5 vol.\% $\mathrm{O}_{2}$ balanced in He. The conversion of the compound in the corresponding oxidation reactions are denoted with $X$. The experimental error was within $\pm 5 \%$.

\section{Figure 5 | Heterogeneous-gas-phase reaction pathways and improvement of the $\mathrm{CH}_{3} \mathrm{Br}$} productivity by optimizing reaction conditions. a) Methane conversion $(X)$ and product selectivity ( $S$ ) versus bed temperature ( $\left.T_{\text {bed }}\right)$ in the gas-phase methane bromination follow similar trends as in the oxybromination of methane over VPO. b) $\mathrm{HBr}$ conversion $(X)$ and yields $(Y)$ of bromine and bromocarbons (carbon-based) versus bed temperature in the oxybromination of methane over VPO indicate the bromine consumption in the gas-phase bromination, ultimately resulting in a formal decrease of the $\mathrm{HBr}$ conversion. c) $\mathrm{CH}_{3} \mathrm{Br}$ selectivity $(S)$ versus space time yield $(S T Y)$ of $\mathrm{CH}_{3} \mathrm{Br}$ production at variable methane concentration, total pressure, and temperature over VPO shows that an excess of methane in the inlet feed is crucial to reach the high selectivity to $\mathrm{CH}_{3} \mathrm{Br}$. d) The single-pass carbon yields of products $(Y)$ and space time yield (STY) of $\mathrm{CH}_{3} \mathrm{Br}$ versus total reactant concentrations at fixed $\mathrm{CH}_{4}: \mathrm{O}_{2}: \mathrm{HBr}$ molar ratio of 4.5:1.5:3 over VPO demonstrate the rather 
stable product distribution and the scalability of the oxybromination processes over the VPO catalyst. The experimental error was within $\pm 5 \%$. Other conditions are specified in Methods.

Figure 6 | The performance of vanadium phosphate in the oxybromination of methane, ethane, and propane. The hydrocarbon conversion $(X)$ as a function of the catalyst bed temperature shows that the temperature onset of the oxybromination reaction decreases in order: methane > ethane > propane, which is in line with a decrease in the $\mathrm{C}-\mathrm{H}$ bond strength. Bromoethane $\left(\mathrm{C}_{2} \mathrm{H}_{5} \mathrm{Br}\right)$ is the principal product observed in the oxybromination of ethane at low reaction temperatures, but in contrast to methane, no polybromoethanes are observed, probably due to their higher propensity to cracking. At higher temperatures, the dehydrobromination pathway is opened resulting in significant ethylene $\left(\mathrm{C}_{2} \mathrm{H}_{4}\right)$ production, with negligible selectivity $(S)$ to $\mathrm{CO}_{2}$. Differently, propane oxybromination cause significant cracking and coking, likely due to the activation of propane on the catalyst surface. The experimental error was within $\pm 5 \%$. Other conditions are stated in Methods. 


\section{Table of contents summary}

Oxybromination is an attractive method for the functionalization of alkanes in natural gas into value-added chemicals and fuels. By reconceiving the high $\mathrm{HBr}$ oxidation activity and the low propensity to combustion, vanadium phosphate was identified as the best catalyst for this reaction.

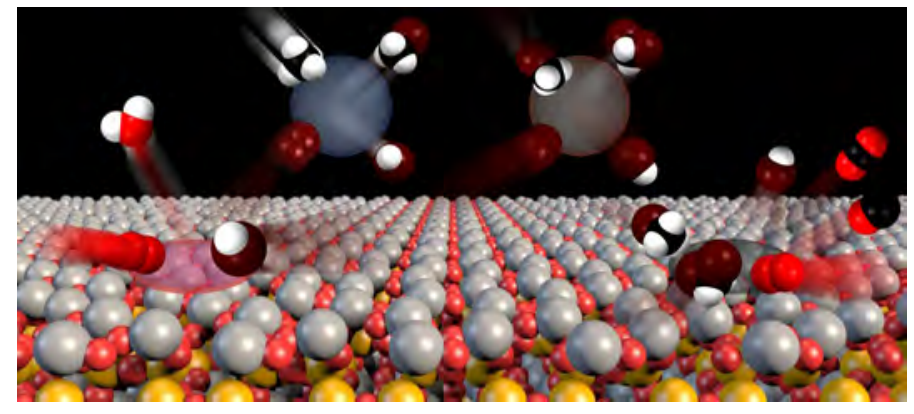




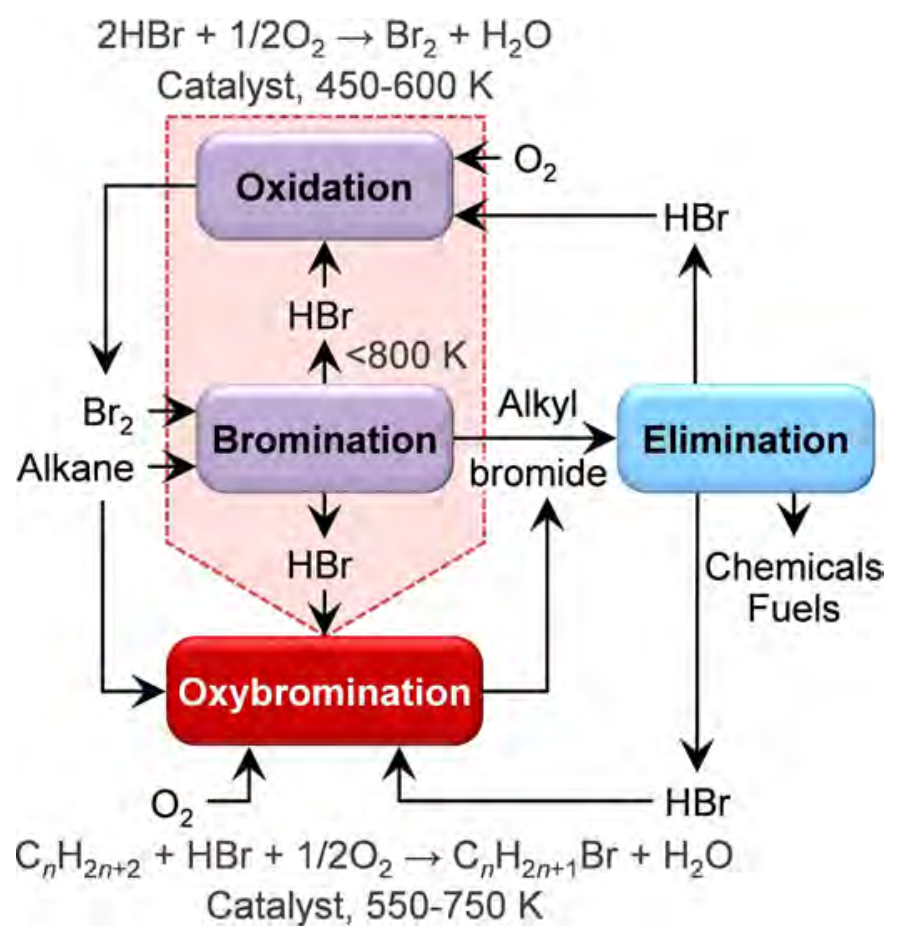

Figure 1 


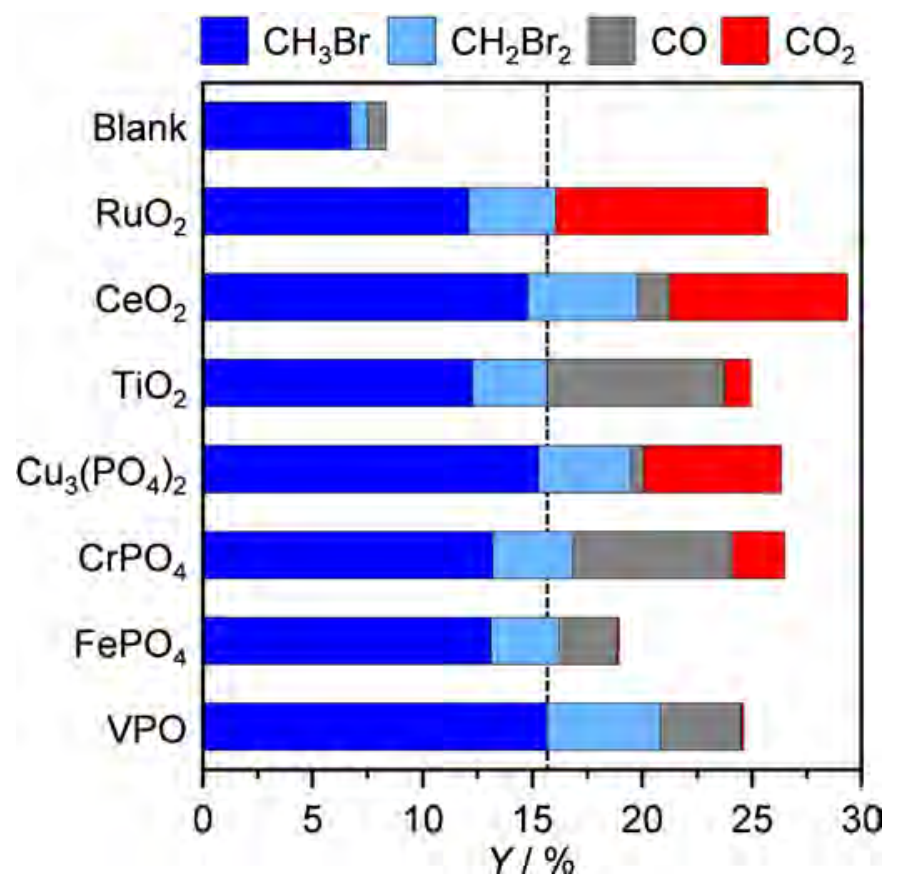

Figure 2 

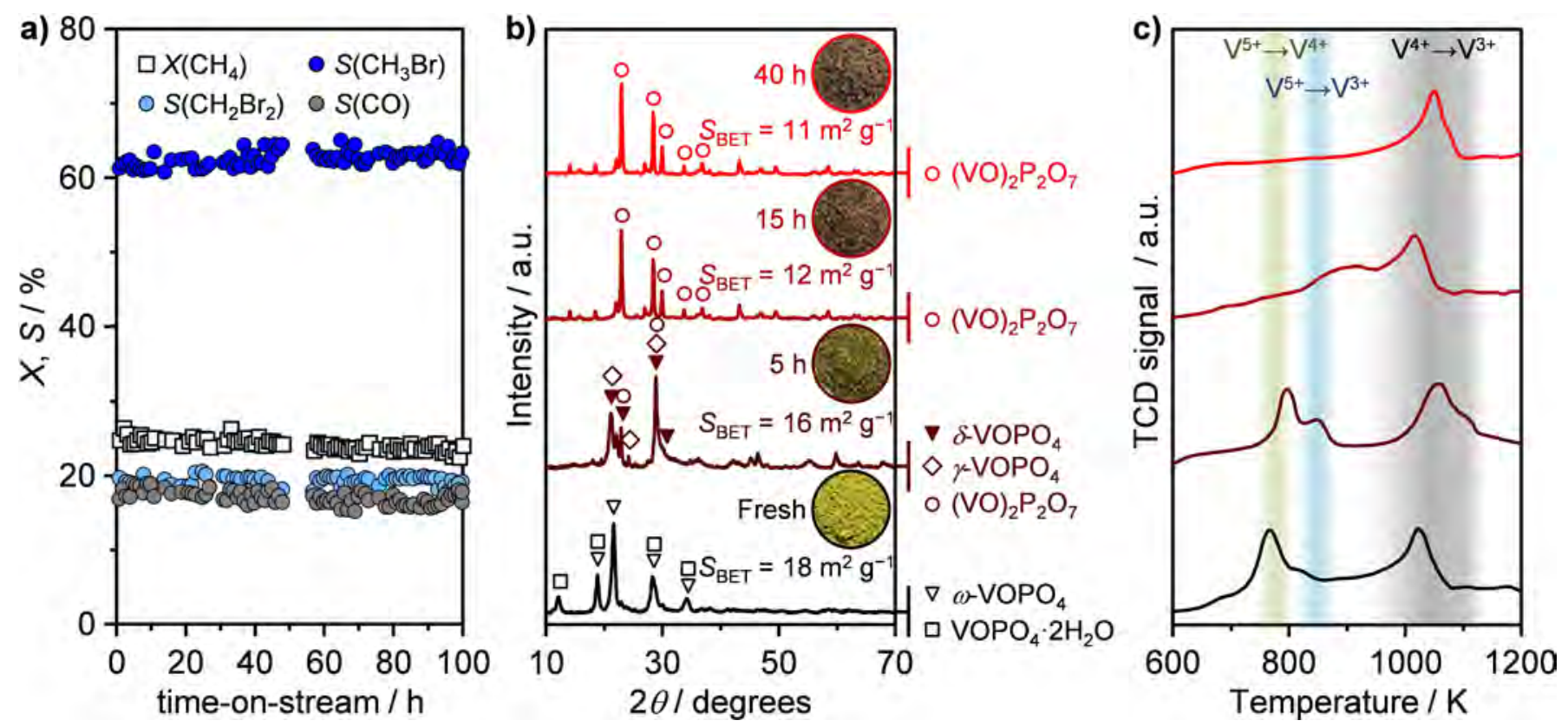

Figure 3 

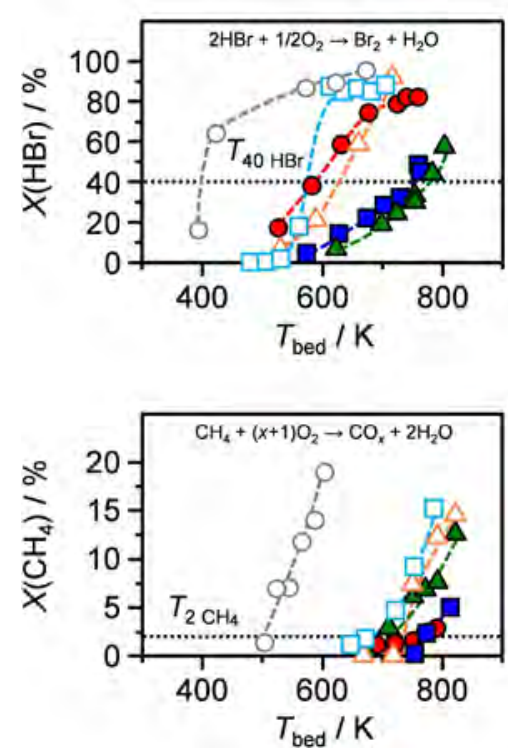
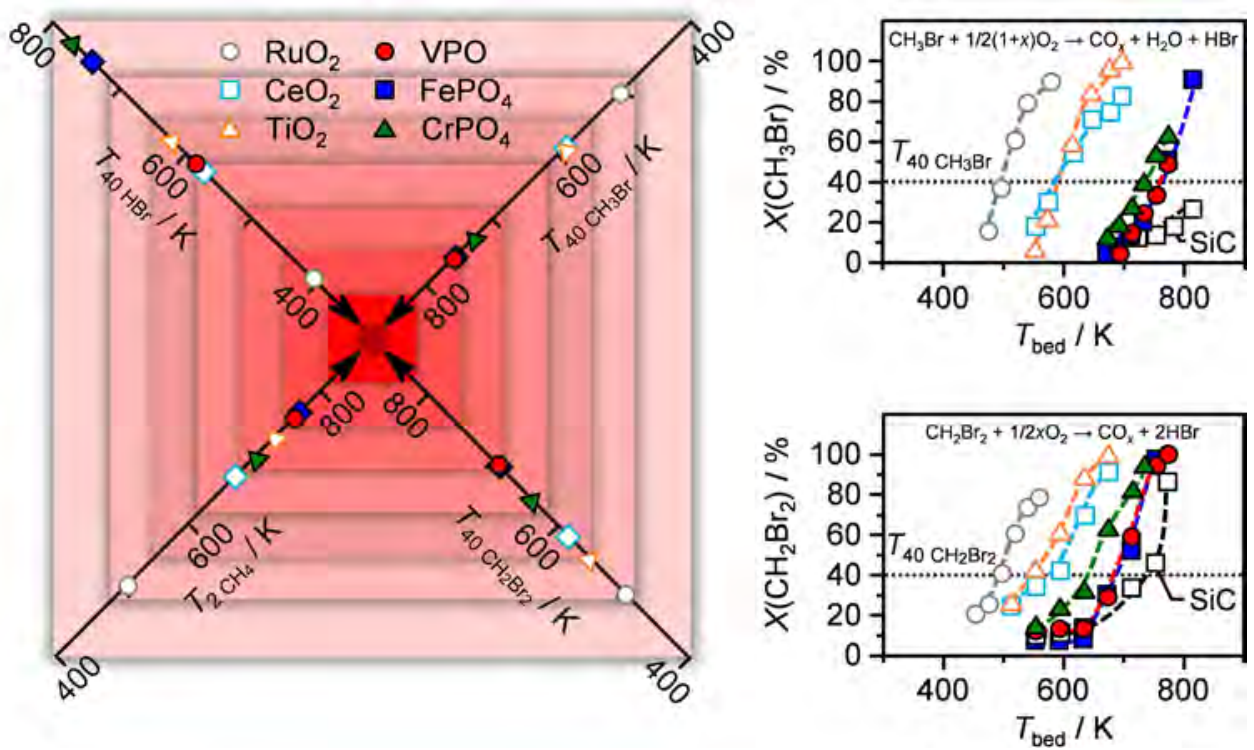

Figure 4 

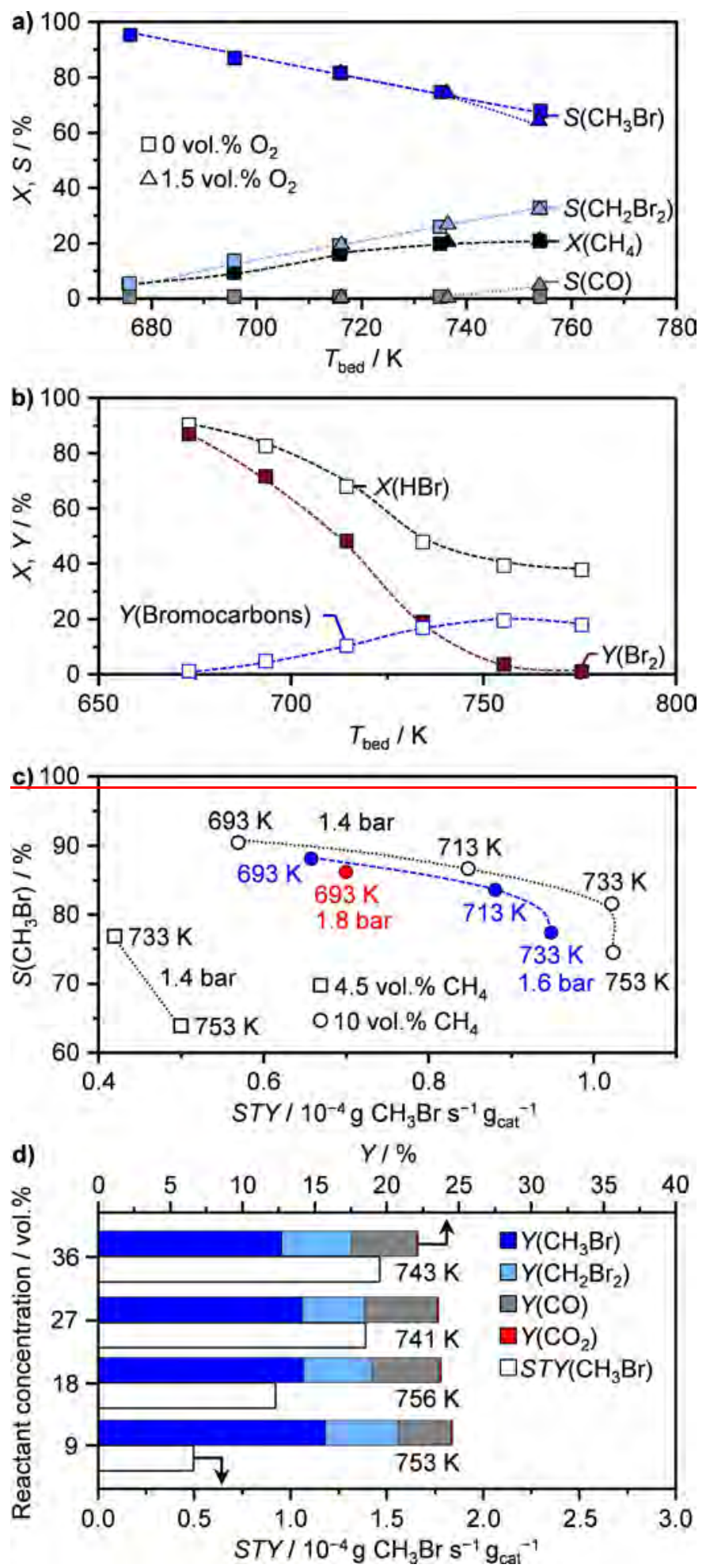

Figure 5 

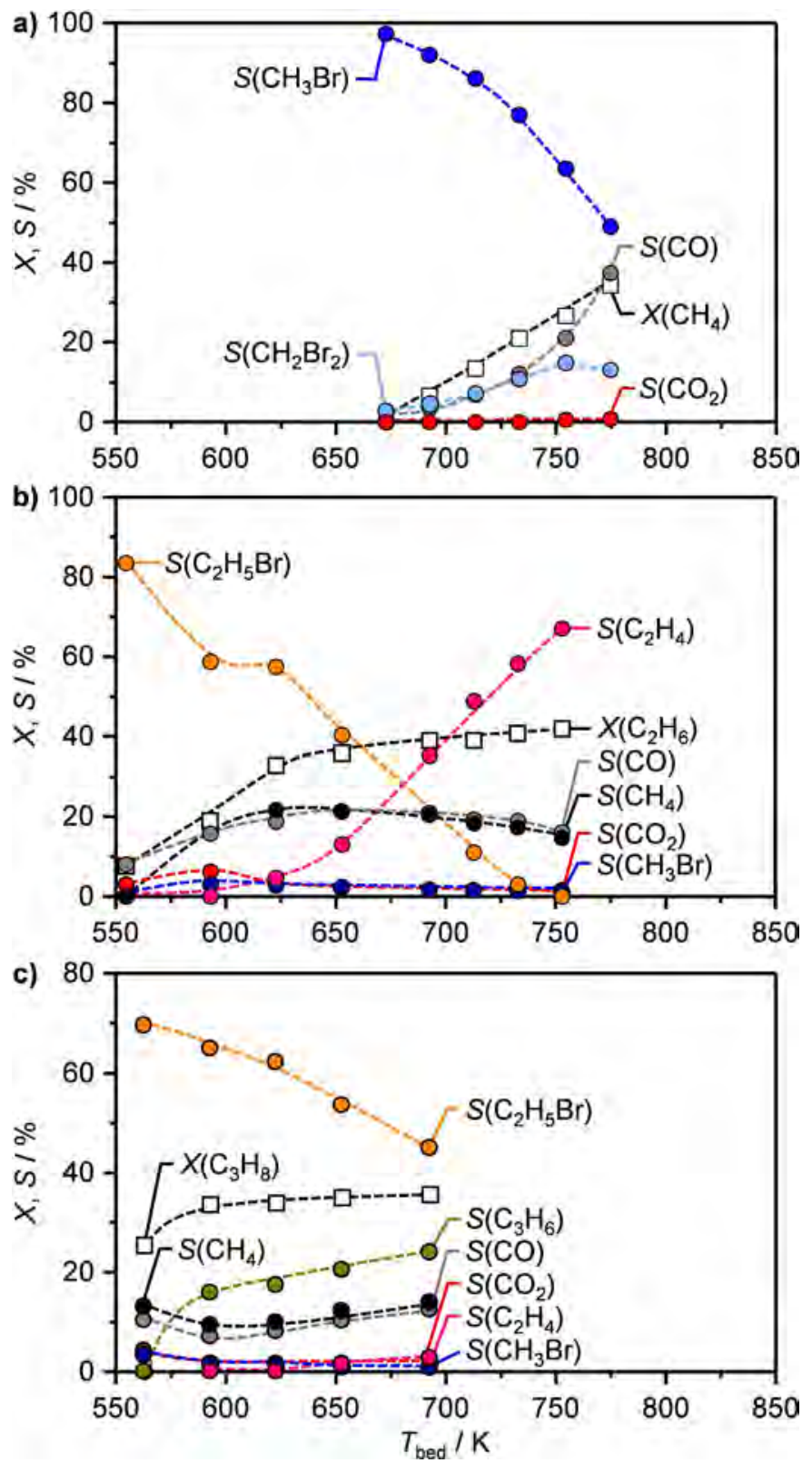

Figure 6 


\section{Supplementary information}

\section{Catalyst design for natural-gas upgrading via oxybromination chemistry}

Vladimir Paunović, Guido Zichittella, Maximilian Moser, Amol P. Amrute, and Javier Pérez-Ramírez*

Further details on the preparation of metal phosphates and catalyst tests, one table, and six figures are incorporated as supporting data. The preparation of $\mathrm{CePO}_{4}, \mathrm{LaPO}_{4}, \mathrm{Ti}_{2} \mathrm{P}_{2} \mathrm{O}_{7}$, $\mathrm{Mn}_{3}\left(\mathrm{PO}_{4}\right)_{2}, \mathrm{CoPO}_{4}, \mathrm{Ni}_{3}\left(\mathrm{PO}_{4}\right)_{2}$, and $\mathrm{Zn}_{3}\left(\mathrm{PO}_{4}\right)_{2}$, studied in this work is detailed. Experimental details on the oxybromination setup, iodometric titration, $\mathrm{HBr}$ analysis in carbonated $\left(\mathrm{Na}_{2} \mathrm{CO}_{3}\right)$ bed, the $\mathrm{HBr}$ oxidation, and the expressions of the catalyst performance (conversion, selectivity, product yield, and carbon balance calculation) are given.

Supplementary Figure 1 schematically displays the catalytic set-up employed to study the oxybromination of methane, ethane, and propane. Supplementary Table 1 shows the catalytic performance of numerous metal phosphates and oxides in the oxybromination of methane. Supplementary Figure 2 presents the X-ray diffractograms of the catalysts prior to and after methane oxybromination and the corresponding variation of the specific surface area. ${ }^{31} \mathrm{P}$ NMR spectra and electron microscopy images of the fresh and spent VPO samples recovered after different exposure times to the oxybromination of methane are displayed in the Supplementary Figures 3 and 4, respectively. Supplementary Figure 5 shows a reactor simulation for methane bromination under the experimental conditions applied to study methane oxybromination. Supplementary Figure 6 presents the oxidative dehydrogenation of $\mathrm{C}_{2} \mathrm{H}_{6}$ and $\mathrm{C}_{3} \mathrm{H}_{8}$ over VPO catalysts under conditions comparable to those applied in the oxybromination of the corresponding alkanes. 
Catalyst preparation. $\mathrm{CePO}_{4}, \mathrm{LaPO}_{4}, \mathrm{Mn}_{3}\left(\mathrm{PO}_{4}\right)_{2}, \mathrm{CoPO}_{4}, \mathrm{Ni}_{3}\left(\mathrm{PO}_{4}\right)_{2}$, and $\mathrm{Zn}_{3}\left(\mathrm{PO}_{4}\right)_{2}$ were prepared by precipitation. For the first two samples, $0.4 \mathrm{M}$ solutions of $\mathrm{Ce}\left(\mathrm{NO}_{3}\right)_{3} \cdot 6 \mathrm{H}_{2} \mathrm{O}$ (Sigma Aldrich, 99.9\%) and $\mathrm{La}\left(\mathrm{NO}_{3}\right)_{3} \cdot 6 \mathrm{H}_{2} \mathrm{O}$ (Sigma Aldrich, $\geq 99.0 \%$ ), respectively, were mixed with a stoichiometric amount of $0.4 \mathrm{M} \mathrm{H}_{3} \mathrm{PO}_{4}$ solution (Sigma Aldrich, $\geq 85 \%$ ) at room temperature. The latter four samples were obtained by mixing the $0.02 \mathrm{M}$ solutions of $\mathrm{MnCl}_{2} \cdot 4 \mathrm{H}_{2} \mathrm{O}$ (Sigma Aldrich, $\geq 99 \%$ ), $\mathrm{Co}\left(\mathrm{NO}_{3}\right)_{2} \cdot 6 \mathrm{H}_{2} \mathrm{O}$ (Acros, 99\%), $\mathrm{Ni}\left(\mathrm{NO}_{3}\right)_{2} \cdot 6 \mathrm{H}_{2} \mathrm{O}$ (Acros, 99\%), and $\mathrm{Zn}\left(\mathrm{NO}_{3}\right)_{2} \cdot 6 \mathrm{H}_{2} \mathrm{O}$ (Sigma Aldrich, $\geq 98 \%$ ), respectively, with a stoichiometric amount of $0.02 \mathrm{M}$ solution of $\mathrm{NaH}_{2} \mathrm{PO}_{4}$ (Sigma Aldrich, $\geq 99.0 \%$ ). All solutions were prepared in deionized water. The resulting suspensions were aged for $2 \mathrm{~h}$ at room temperature. The precipitates were then separated by filtration, extensively washed with deionized water, dried in vacuum (50 mbar) at $373 \mathrm{~K}$ for $24 \mathrm{~h}$, and calcined in a static air at $823 \mathrm{~K}\left(5 \mathrm{~K} \mathrm{~min}^{-1}\right)$ for $5 \mathrm{~h}$. $\mathrm{Ti}_{2} \mathrm{P}_{2} \mathrm{O}_{7}$ was synthesized by reacting the $\mathrm{TiO}_{2}$-rutile (Aldrich, nanopowder, 99.5\%) with the $\mathrm{H}_{3} \mathrm{PO}_{4}$ in molar ratio Ti:P = 1:3 at room temperature. The resulting paste was mixed overnight at the room temperature and dried under static air at $523 \mathrm{~K}$ for $2 \mathrm{~h}$. The thus obtained solid was washed with deionized water to remove unreacted phosphorous species and calcined at $823 \mathrm{~K}\left(5 \mathrm{~K} \mathrm{~min}^{-1}\right)$ for $5 \mathrm{~h}$. The structures of the all above mentioned phosphate catalysts were confirmed by the XRD analysis.

Oxybromination setup. The setup for catalyst testing is schematically depicted in Supplementary Figure 1. It consists of (i) mass flow controllers to feed alkane $\left(\mathrm{CH}_{4}, \mathrm{C}_{2} \mathrm{H}_{6}\right.$, or $\mathrm{C}_{3} \mathrm{H}_{8}$ ), $\mathrm{HBr}, \mathrm{O}_{2}, \mathrm{Ar}$, and $\mathrm{He}$, (ii) an electrically heated oven hosting a quartz micro reactor equipped with a K-type thermocouple embedded in the quartz thermowell in direct contact with the catalyst bed, (iii) downstream heat liner to avoid any condensation of the reactants and products, (iv) an electrically heated oven hosting a carbonated bed to react with the unreacted $\mathrm{HBr}$, and (v) GC-MS for on-line analysis and an impinger bottle containing KI 
solution to collect bromine for off-line analysis. The effluent stream was finally sent through two impinging bottles containing concentrated $\mathrm{KI}$ and $\mathrm{NaOH}$ solutions, respectively, for neutralization.

Analysis method. The analyses were conducted using an off-line Mettler Toledo G20

Compact Titrator for bromine quantification and an on-line GC-MS (Agilent GC 6890, MS 5973N) for directly quantify $\mathrm{CH}_{4}, \mathrm{CH}_{3} \mathrm{Br}, \mathrm{CH}_{2} \mathrm{Br}_{2}, \mathrm{Ar}, \mathrm{CO}, \mathrm{CO}_{2}$, and indirectly $\mathrm{HBr}$ at the reactor outlet.

(i) $\mathrm{The} \mathrm{Br}_{2}$ content was measured by iodometric titration of triiodide (Eq.1), formed by the reaction of the produced $\mathrm{Br}_{2}$ with aqueous $\mathrm{KI}$ (Eq.2), with a $0.01 \mathrm{M}$ sodium thiosulfate solution (Aldrich, 99.99\%).

$$
\begin{aligned}
& \mathrm{I}_{3}{ }^{-}+2 \mathrm{~S}_{2} \mathrm{O}_{3}{ }^{2-} \rightarrow 3 \mathrm{I}^{-}+\mathrm{S}_{4} \mathrm{O}_{6}{ }^{2-} \\
& 3 \mathrm{I}^{-}+\mathrm{Br}_{2} \rightarrow \mathrm{I}_{3}^{-}+2 \mathrm{Br}^{-} \quad \text { Eq. } 2
\end{aligned}
$$

(ii) The $\mathrm{HBr}$ content at the reactor outlet was determined by feeding the effluent gas stream through a heated carbonate bed containing anhydrous $\mathrm{Na}_{2} \mathrm{CO}_{3}(\mathrm{Sigma}$ Aldrich, $>99 \%$ ) according to Eq. 3 .

$$
2 \mathrm{HBr}+\mathrm{Na}_{2} \mathrm{CO}_{3} \rightarrow 2 \mathrm{NaBr}+\mathrm{H}_{2} \mathrm{O}+\mathrm{CO}_{2}
$$

The generated $\mathrm{CO}_{2}$ was quantified by GC-MS. Finally, the amount of $\mathrm{HBr}$ at the reactor outlet was determined according to Eq. 4.

$$
n(\mathrm{HBr})^{\text {outlet }}=2 \times\left(n\left(\mathrm{CO}_{2}\right)_{\mathrm{CS}}^{\text {outlet }}-n\left(\mathrm{CO}_{2}\right)_{\mathrm{RS}}^{\text {outlet }}\right), \text { mol }
$$

where $n\left(\mathrm{CO}_{2}\right)$ indicates the amount of $\mathrm{CO}_{2}$ at the reactor outlet, superscript $\mathrm{CS}$ (carbonated sample) refers to the sample which was admitted through a carbonated bed, and superscript RS (reaction sample) denotes the sample taken when bypassing the carbonate bed. 
(iv) The conversion of alkanes $\left(\mathrm{CH}_{4}, \mathrm{C}_{2} \mathrm{H}_{6}, \mathrm{C}_{3} \mathrm{H}_{8}\right)$, haloalkanes $\left(\mathrm{CH}_{3} \mathrm{Br}, \mathrm{CH}_{2} \mathrm{Br}_{2}\right)$ and $\mathrm{HBr}$ was determined by Eq. 5 .

$$
X(j)=\frac{n(j)^{\text {inlet }}-n(j)^{\text {outlet }}}{n(j)^{\text {inlet }}} \times 100, \%
$$

where $n(j)$ is the amount of the corresponding compound $j$ expressed in moles.

(v) Selectivity $(S(i))$ and yield $(Y(i))$ to product $i$, and the relative error in carbon balance ( $\varepsilon(\mathrm{C}$-balance $))$, were determined according to Eq. 6, Eq. 7, and Eq. 8 respectively.

$$
\begin{array}{cc}
S(i)=\frac{n(i) \times N_{C}(i)}{\sum_{i=1}^{\text {outlet }} n(i) \times N_{C}(i)} \times 100, \% & \text { Eq. } 6 \\
Y(i)=S(i) \times X(j), \% & \text { Eq. } 7 \\
\varepsilon(\text { C-balance })=\frac{\sum_{i=1}^{\text {inlet }} n(i) \times N_{C}(i)-\sum_{i=1}^{\text {outlet }} n(i) \times N_{C}(i)}{\sum_{i=1}^{\text {inlet }} n(i) \times N_{C}(i)} \times 100, & \text { Eq. } 8
\end{array}
$$

where $n(i)$ is the amount of the species $i$ expressed in moles, $N_{C}(i)$ is the number of carbon atoms in the corresponding compound $i$.

Heat and mass transfer limitations. Based on criterion for external and criterion for internal heat transfer limitations that are suggested by Mears, D. E. in J. Catal. 20, 127-131 (1971) measurements are free of external and internal heat transfer limitations. The contribution of the external and internal mass transport artefacts were ruled out based on Mears (Mears, D. E. Ind. Eng. Chem. Process Des. Dev. 10, 541-547 (1971)) and Weisz-Prater criterion (Weisz, P. B. and Prater, C. D, Adv. Catal. 6, 143-196 (1954)), respectively, that were estimated for isothermal operation regime and typical conditions applied in our experiments. 
Reactor modeling. The concentration profile of the reactants, intermediates, and products for the gas-phase bromination were modeled using a reaction network (Eq. 9-13) with the kinetic and thermodynamic parameters reported by Ding, K. et al.in ACS Catal. 3, 474-477 (2013).

$$
\begin{array}{cc}
\mathrm{Br}_{2}+\mathrm{M} \leftrightarrow 2 \mathrm{Br}^{*}+\mathrm{M} & \text { Eq. } 9 \\
\mathrm{Br}^{*}+\mathrm{CH}_{4} \leftrightarrow \mathrm{CH}_{3} *+\mathrm{HBr} & \text { Eq. } 10 \\
\mathrm{CH}_{3}^{*}+\mathrm{Br}_{2} \leftrightarrow \mathrm{CH}_{3} \mathrm{Br}+\mathrm{Br} * & \text { Eq. } 11 \\
\mathrm{CH}_{3} \mathrm{Br}+\mathrm{Br}^{*} \leftrightarrow \mathrm{CH}_{2} \mathrm{Br}^{*}+\mathrm{HBr} & \text { Eq. } 12 \\
\mathrm{CH}_{2} \mathrm{Br}^{*}+\mathrm{Br}_{2} \leftrightarrow \mathrm{CH}_{2} \mathrm{Br}_{2}+\mathrm{Br}^{*} & \text { Eq. } 13
\end{array}
$$

The simulations were conducted using MATLAB ${ }^{\odot}$ assuming a homogeneous model with ideal plug-flow behavior under isothermal $(T=753 \mathrm{~K})$ and isochoric conditions for the inlet feed containing 4.5 vol. $\% \mathrm{CH}_{4}$ and 1.5 vol. $\% \mathrm{Br}_{2}$ at 1.4 bar reaction pressure. 


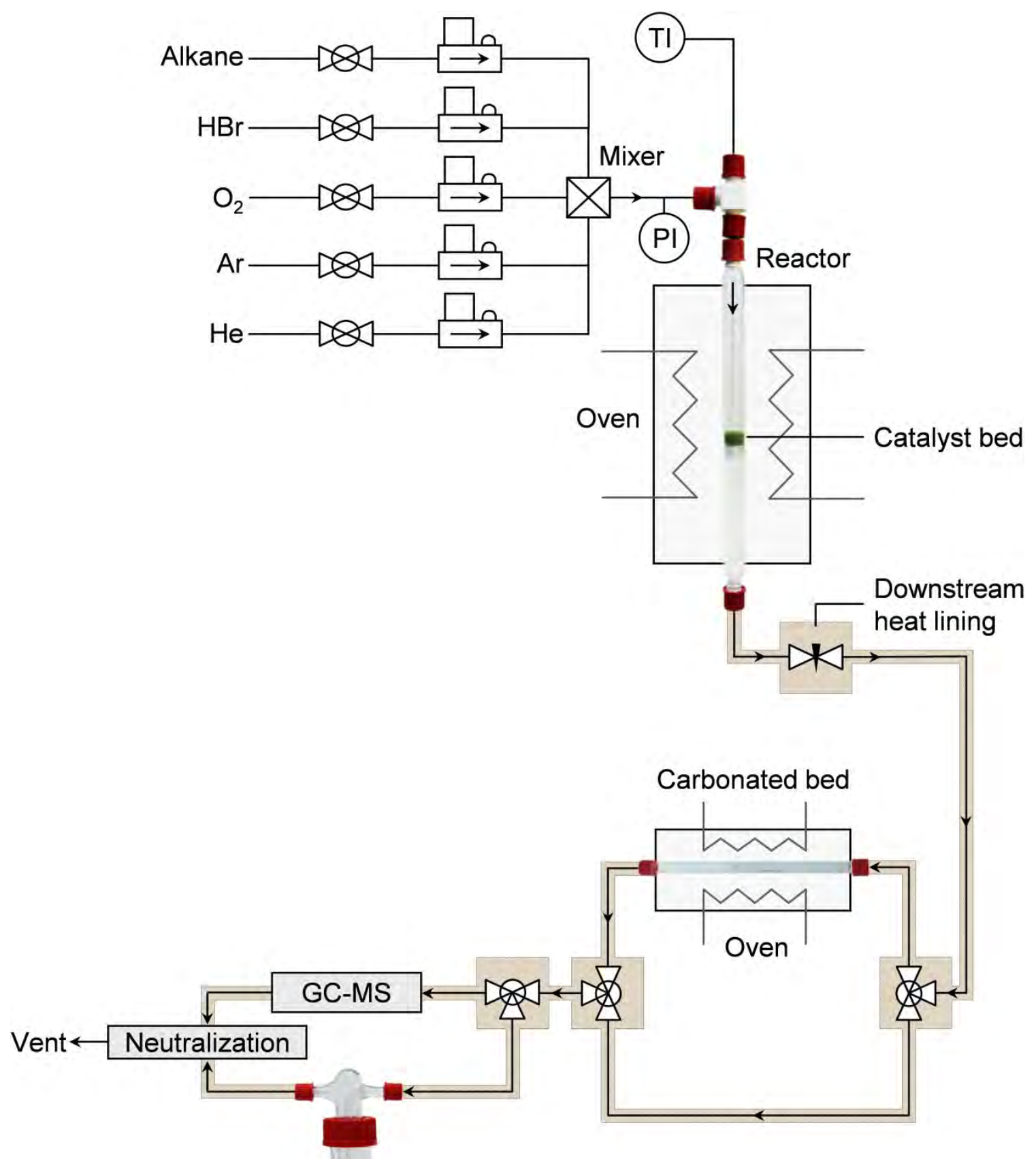

lodometric titration

Supplementary Figure 1 | A schematic of the catalytic set-up employed to study the oxybromination of alkanes. 


\section{Supplementary Table 1 | Performance of the catalysts in the oxybromination of}

\section{methane. ${ }^{a}$}

\begin{tabular}{|c|c|c|c|c|c|}
\hline$\overline{\text { Catalyst }}$ & $\begin{array}{c}X\left(\mathrm{CH}_{4}\right) \\
(\%)\end{array}$ & $\begin{array}{c}S\left(\mathrm{CH}_{3} \mathrm{Br}\right) \\
(\%)\end{array}$ & $\begin{array}{c}S\left(\mathrm{CH}_{2} \mathrm{Br}_{2}\right) \\
(\%)\end{array}$ & $\begin{array}{c}S(\mathrm{CO}) \\
(\%)\end{array}$ & $\begin{array}{c}S\left(\mathrm{CO}_{2}\right) \\
(\%)\end{array}$ \\
\hline Blank & 8.0 & $82 \pm 3.4(6.6)^{b}$ & $10 \pm 2(0.8)$ & $8 \pm 2.5(0.6)$ & $0(0)$ \\
\hline $\mathrm{CePO}_{4}$ & 9.5 & $70 \pm 2(6.6)$ & $7 \pm 1(0.7)$ & $22 \pm 2.1(2.1)$ & $1 \pm 0.2(0.1)$ \\
\hline $\mathrm{LaPO}_{4}$ & 8.7 & $85 \pm 0.6(7.4)$ & $11.0 \pm 0.6(1.0)$ & $4 \pm 1(0.3)$ & $0(0)$ \\
\hline $\mathrm{Ti}_{2} \mathrm{P}_{2} \mathrm{O}_{7}$ & 8.9 & $66 \pm 2(5.9)$ & $9 \pm 1.2(0.8)$ & $25 \pm 2(2.2)$ & $0(0)$ \\
\hline $\mathrm{Mn}_{3}\left(\mathrm{PO}_{4}\right)_{2}$ & 6.3 & $68 \pm 1.1(4.3)$ & $0(0)$ & $31 \pm 2(1.9)$ & $1 \pm 0.1(0.1)$ \\
\hline $\mathrm{CoPO}_{4}$ & 8.4 & $73 \pm 2(6.1)$ & $9 \pm 1.3(0.8)$ & $18 \pm 3(1.5)$ & $0(0)$ \\
\hline $\mathrm{Ni}_{3}\left(\mathrm{PO}_{4}\right)_{2}$ & 10.8 & $74 \pm 2.1(8.0)$ & $9 \pm 1.5(1.0)$ & $12 \pm 4(1.3)$ & $5 \pm 0.9(0.5)$ \\
\hline $\mathrm{Zn}_{3}\left(\mathrm{PO}_{4}\right)_{2}$ & 8.2 & $84 \pm 3(6.9)$ & $5 \pm 1(0.4)$ & $11 \pm 2.5(0.9)$ & $0(0)$ \\
\hline $\mathrm{Cu}_{3}\left(\mathrm{PO}_{4}\right)_{2}$ & 27.0 & $57 \pm 2(15.4)$ & $16 \pm 1.7(4.3)$ & $4 \pm 0.5(1.1)$ & $23 \pm 1(6.2)$ \\
\hline $\mathrm{CrPO}_{4}$ & 26.4 & $50 \pm 1.1(13.2)$ & $14.0 \pm 0.4(3.7)$ & $27 \pm 2(7.1)$ & $9 \pm 1(2.4)$ \\
\hline VPO & 24.5 & $64 \pm 1.3(15.7)$ & $20.5 \pm 1(5.0)$ & $15 \pm 1(3.7)$ & $0.5 \pm 0.05(0.1)$ \\
\hline $\mathrm{FePO}_{4}$ & 19.1 & $68 \pm 1.5(13.0)$ & $16.6 \pm 0.5(3.2)$ & $15 \pm 1.4(2.9)$ & $0.4 \pm 0.05(0.1)$ \\
\hline $\mathrm{FePO}_{4} / \mathrm{SiO}_{2}$ & 26.0 & $56.3 \pm 0.7(14.6)$ & $22.6 \pm 0.5(5.9)$ & $19.5 \pm 0.9(5.1)$ & $1.6 \pm 0.6(0.4)$ \\
\hline $\mathrm{RuO}_{2}$ & 26.0 & $46.7 \pm 0.9(12.1)$ & $15.2 \pm 0.9(4.0)$ & $0(0)$ & $38.1 \pm 0.8(9.9)$ \\
\hline $\mathrm{TiO}_{2}$ & 25.0 & $49.1 \pm 0.3(12.3)$ & $13.6 \pm 0.6(3.4)$ & $32.6 \pm 0.6(8.1)$ & $4.7 \pm 0.1(1.2)$ \\
\hline $\mathrm{CeO}_{2}$ & 29.0 & $52 \pm 1.5(15.1)$ & $18.3 \pm 0.8(5.3)$ & $0(0)$ & $29.7 \pm 0.9(8.6)$ \\
\hline
\end{tabular}

${ }^{a}$ Conditions: $W_{\text {cat }}=1.0 \mathrm{~g}\left(d_{P}=0.4-0.6 \mathrm{~mm}\right), T_{\text {bed }}=753 \mathrm{~K}, P=1.3 \mathrm{bar}$,

$F_{\mathrm{T}}=100 \mathrm{~cm}^{3} \mathrm{STP} \mathrm{min}^{-1}$ containing 4.5 vol. $\% \mathrm{CH}_{4}, 3$ vol. $\% \mathrm{HBr}, 1.5$ vol. $\% \mathrm{O}_{2}$, and 3 vol.\% Ar (internal standard) balanced in He. Data were collected after $1 \mathrm{~h}$ on stream over each catalyst. Conversion $(X)$ and selectivities $(S)$ are calculated as an average of minimum three measurements. The error in the reported conversion values was less than $2 \%$.

${ }^{b}$ Single-pass carbon yields of reaction products in brackets. 


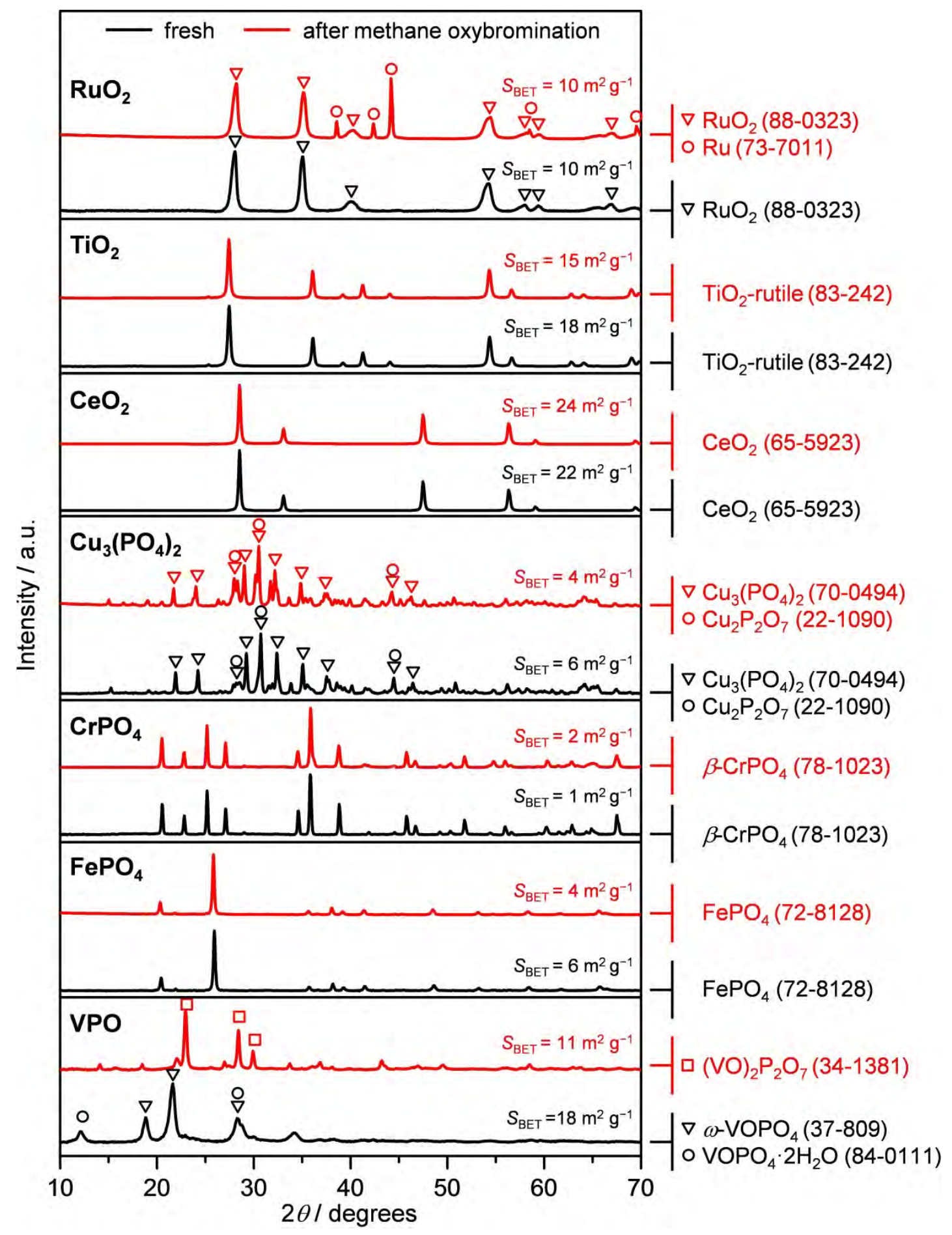

Supplementary Figure $2 \mid \mathrm{X}$-ray diffractograms and total surface area of the fresh and used oxide and phosphate catalysts. The crystalline phases identified in the samples are listed on the right panel and $S_{\mathrm{BET}}$ are indicated above the corresponding patterns. Experimental details on the X-ray diffraction analysis are given in Methods. 


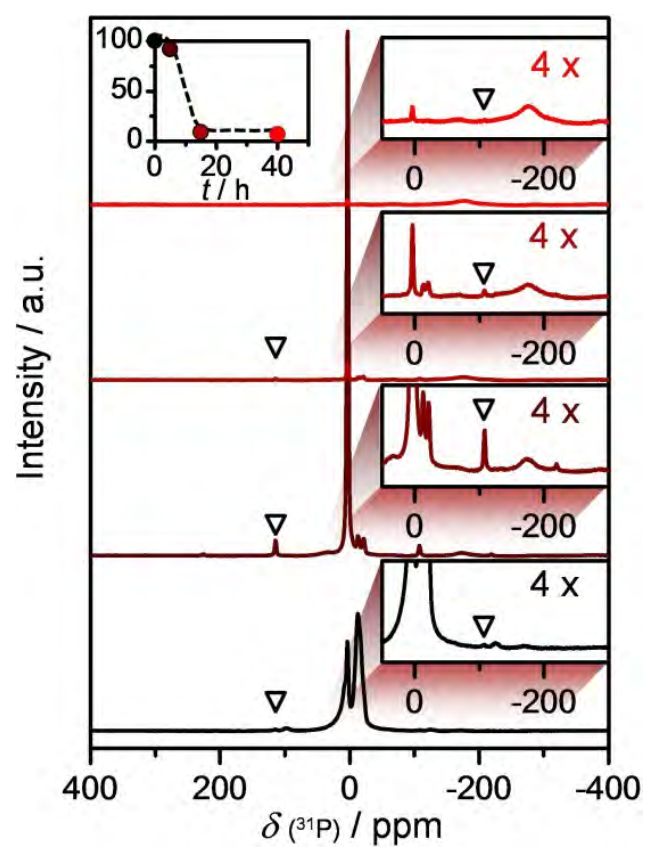

Supplementary Figure $3 \mid{ }^{31} \mathbf{P}$ Nuclear magnetic resonance spectra of the fresh and used VPO samples recovered after equilibration under methane oxybromination conditions

for a different time on stream. The ${ }^{31} \mathrm{P}$ NMR signals which are located at around $0 \mathrm{ppm}$, correspond to the phosphorous atoms in close vicinity to the $\mathrm{V}^{5+}$ states in the VPO phases ${ }^{41,42}$ and were gradually vanishing over time. In contrary, the signal positioned at around -175 ppm, ascribed to the $\mathrm{P}$ surrounding a defect $\mathrm{V}^{5+}$ states $^{41}$ was gradually increasing over time. Nevertheless, the overall integral of the $\mathrm{V}^{5+}$ was stabilized after $15 \mathrm{~h}$ on stream (see inset in the top left corner). The spinning side bands are denoted with. Experimental details on ${ }^{31} \mathrm{P}$ NMR analysis are given in Methods. 


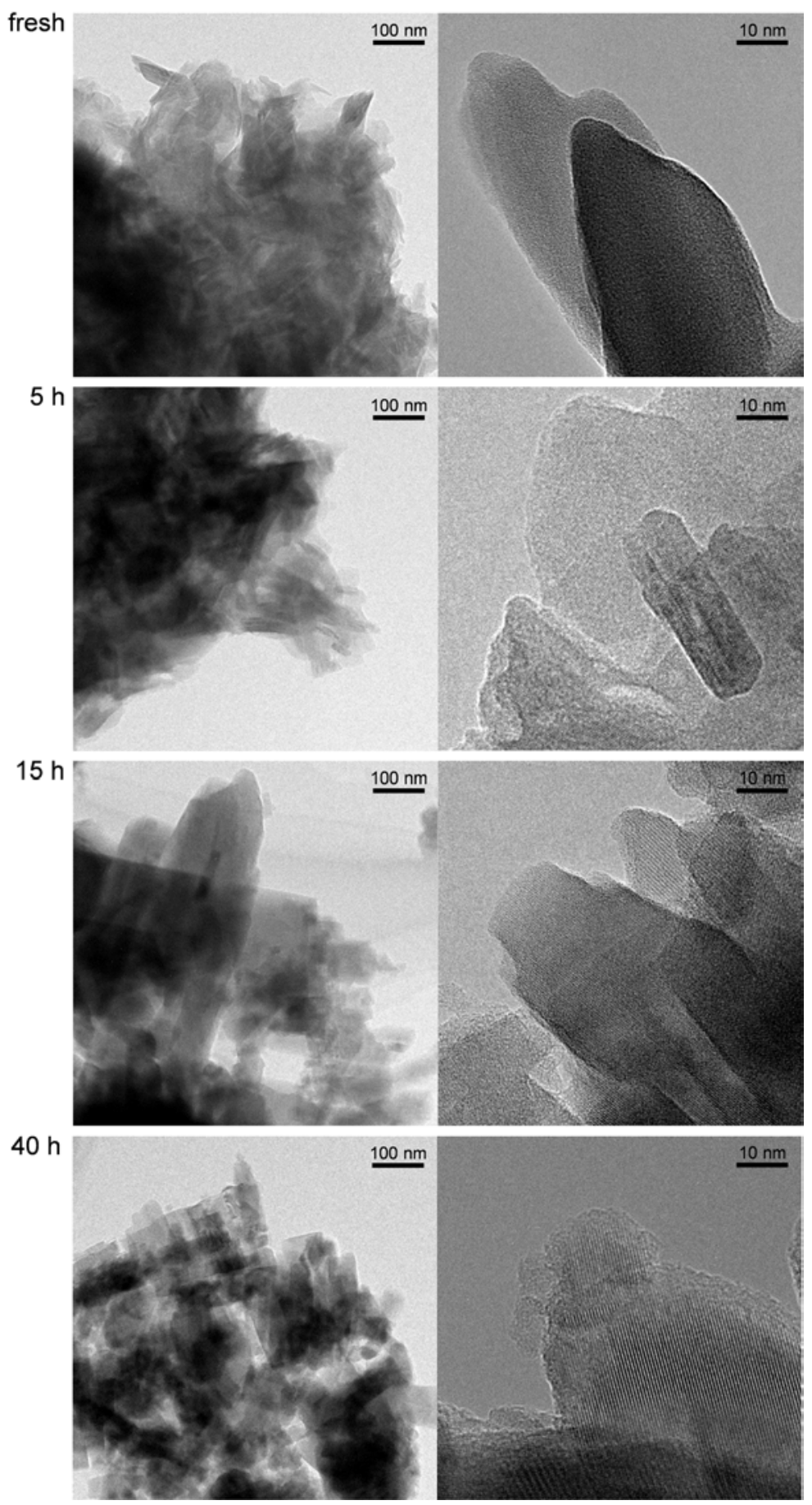

Supplementary Figure 4 | High-resolution transmission electron micrographs of VPO samples before and after equilibration under the oxybromination of methane for different times. Experimental details on HRTEM analysis are given in Methods. 

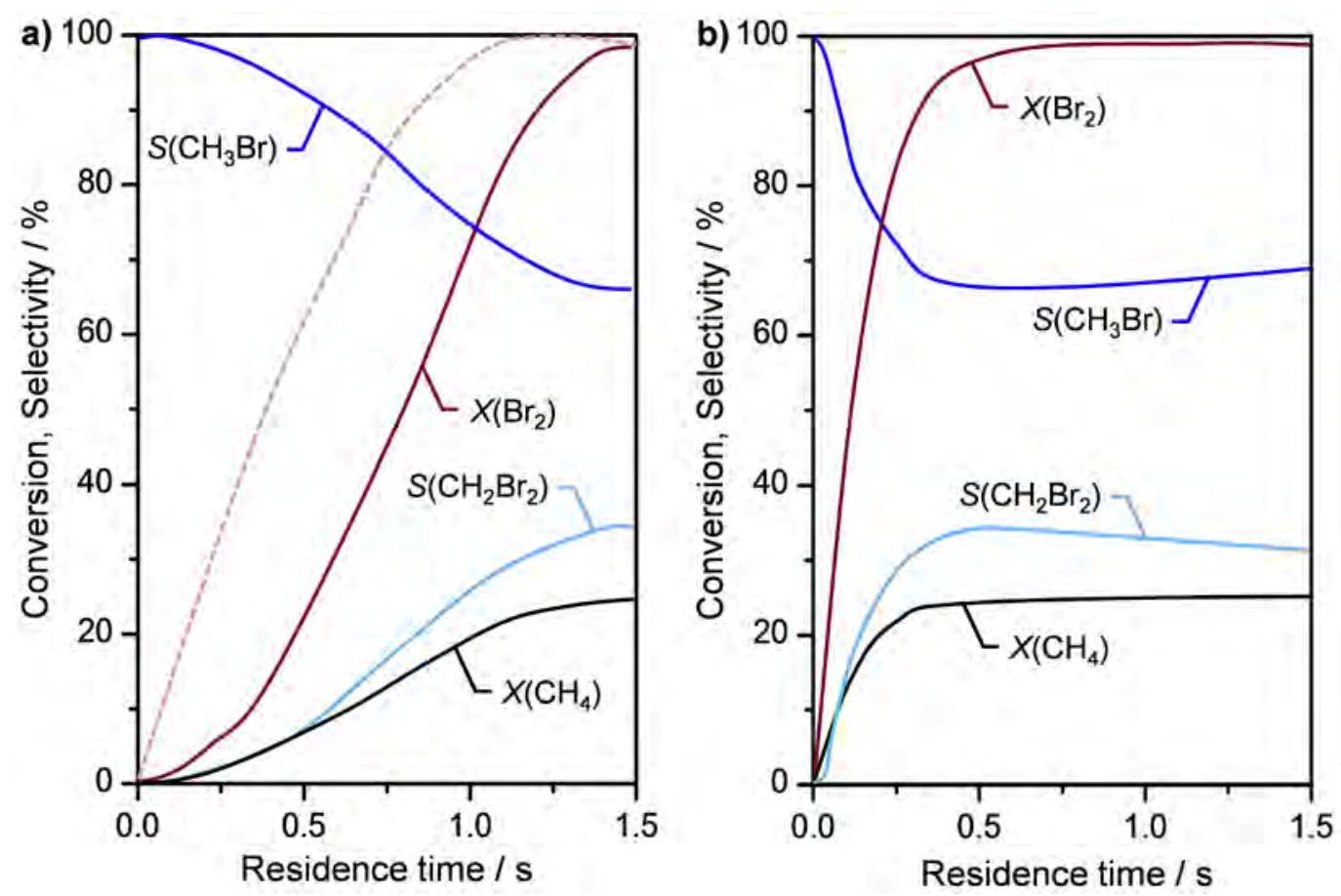

\section{Supplementary Figure 5 | Simulation of the methane bromination in a plug-flow reactor.}

a) Simulation predicts relatively a low conversion of methane at short residence times up to ca. $0.4 \mathrm{~s}$ and a sharp increase in conversion from $c a .0 .4$ till $c a .1 \mathrm{~s}$. This residence time interval is comparable with the residence time estimated according to the void volume between the catalyst particles under typical oxybromination conditions (bed volume $\sim 1$ $2 \mathrm{~cm}^{3}$, particle size $=0.4-0.6 \mathrm{~mm}$, and bed porosity $\left.(\varepsilon)=0.4, T=753 \mathrm{~K}\right)$, which is in the order of $0.4-0.5 \mathrm{~s}$. The normalized concentration of the bromine radicals indicated by the dashed line suggests relatively high concentration of these reactive species already at very short residence times. b) Simulation is made for the limiting case when the bromine dissociation (Eq.9) is in equilibrium. It predicts even shorter residence time (ca. $0.5 \mathrm{~s}$ ) is sufficient to reach $c a .22 \%$ of methane conversion. 

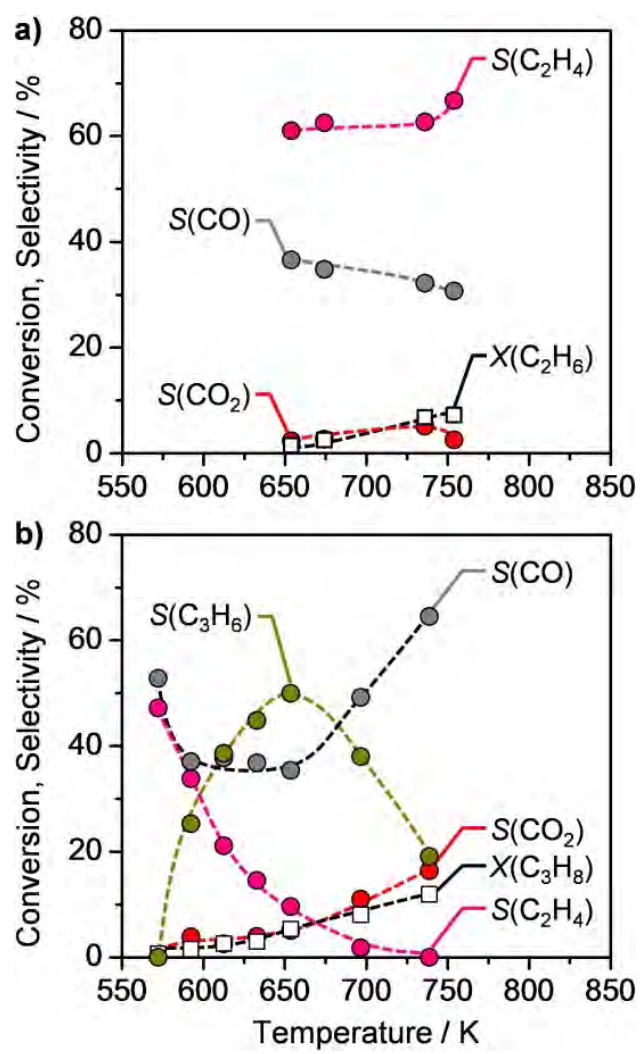

Supplementary Figure 6 | Oxidative dehydrogenation of ethane a) and propane b) over VPO catalyst. Conditions: a) oxidative dehydrogenation of ethane $\left(\mathrm{C}_{2} \mathrm{H}_{6}\right): W_{\text {cat }}=1.0 \mathrm{~g}$, $P=1.4$ bar, $F_{\mathrm{T}}=100 \mathrm{~cm}^{3} \mathrm{STP} \mathrm{min}^{-1}$ containing 4.5 vol. $\% \mathrm{C}_{2} \mathrm{H}_{6}$ and 1.5 vol. $\% \mathrm{O}_{2}$ balanced in $\mathrm{He}$; b) oxidative dehydrogenation of propane $\left(\mathrm{C}_{3} \mathrm{H}_{8}\right): W_{\text {cat }}=1.0 \mathrm{~g}, P=1.4$ bar, $F_{\mathrm{T}}=100 \mathrm{~cm}^{3} \mathrm{STP} \mathrm{min}^{-1}$ containing 4.5 vol. $\% \mathrm{C}_{3} \mathrm{H}_{8}$ and 1.5 vol. $\% \mathrm{O}_{2}$ balanced in $\mathrm{He}$. 